Check for updates

Cite this: Mater. Adv., 2021, 2,6197

Received 25th May 2021, Accepted 26th August 2021

DOI: $10.1039 / \mathrm{d} 1 \mathrm{ma} 00467 \mathrm{k}$

rsc.li/materials-advances

\section{Functionalized graphene oxide materials for the fluorometric sensing of various analytes: a mini review}

\author{
Sivasubramanian Suguna, $\uparrow$ Charles Immanuel David, (D) $\dagger$ Jeyaraj Prabhu* and \\ Raju Nandhakumar (DD *
}

\begin{abstract}
Among diverse nanomaterials, graphene oxide (GO) and reduced graphene oxide (rGO)-based nanomaterials have encountered generous attention because of their ubiquitous advantages such as photo-stability, nontoxicity, water-solubility, bio-compatibility, eco-friendliness, and cost-effectiveness. Unfortunately, the inadequacy of functional groups in graphene-based nanomaterials seriously obstructs the complexing ability with regard to analytes in the field of fluorescent chemosensors. Therefore, graphene oxide and reduced graphene oxide-based materials were functionalized/modified using organic fluorophores, organic acids, polymers, organic dyes, inorganic nanoparticles, macrocyclic compounds, rotaxanes, DNA, metal oxides, chemodosimeter molecules, etc. They find extensive applications in the field of fluorescence sensing as chemosensors, wherein they either perform as fluorophores or quenchers. The functionalization is typically supported by covalent and noncovalent interactions including electrostatic forces, $\pi-\pi$ interaction, and hydrogen bonding to furnish effective photophysical properties for fluorescent chemosensor applications. In this mini review, we critically discuss the sensitive and selective recognition of biologically and environmentally important metal ions, anions, neutral molecules, and small biological scaffolds via divergent signalling phenomena such as photoinduced electron transfer (PET), fluorescence resonance energy transfer (FRET), intramolecular charge transfer (ICT), energy transfer (ET), excited state intramolecular proton transfer (ESIPT), aggregation induced emission (AIE), and displacement approach. Most of the discussed functionalized graphene oxide materials show high sensitivity toward various analytes compared to other potential fluorescent chemosensors.
\end{abstract}

\section{Introduction}

\subsection{Fluorescent chemosensors}

The chemical species enriched with fluorescent characteristics that enable interaction with the analyte and signalling through easily measurable properties, including electrical, electronic, thermal, magnetic, and, in particular, optical changes, are named as fluorescent chemosensors. ${ }^{1-4}$ In general, optical signalling chemosensors are designed based on the photophysical changes upon the detection of various kinds of analytes, such as metal cations, anions, neutral molecules, and small biological scaffolds via the supramolecular hostguest chemistry ${ }^{5-9}$ Moreover, fluorescent chemosensors have acquired considerable attention on account of their promising

Department of Applied Chemistry, Karunya Institute of Technology and Sciences,

(Deemed-to-be University), Karunya Nagar, Coimbatore - 641 114, India.

E-mail: nandhakumar@karunya.edu,prabhuj@karunya.edu

$\dagger$ These authors contributed equally to this work. onsight and quick detection with a low limit of detection for analytes. Hence, a chemical intercessor element (responsible for the analyte detection) and a transducer (responsible for measurable signal conversion) are two major functional units required for producing signals upon the binding of various analytes to prove its presence by the way of photophysical property changes (absorption, fluorescence, relaxivity, etc.).$^{10-13}$

Basically, analyte detection is achieved by observing the photophysical process of the fluorescent chemosensors employing the binding and signalling approach, in particular, PET, FRET, ICT, ET, ESIPT, AIE mechanisms, and displacement approach. ${ }^{14-23}$ In recent times, fluorescent chemosensors have gradually become a pace-setter compared to other traditional analytical techniques (e.g., atomic emission spectrometry, neutron activation analysis, inductively coupled plasma spectrometry, mass spectrometry, Raman scattering, electrothermal atomic absorption spectrometry, atomic absorption spectrometry, and voltammetry) because of their advantages such as high sensitivity and selectivity, a low concentration of analyte, 


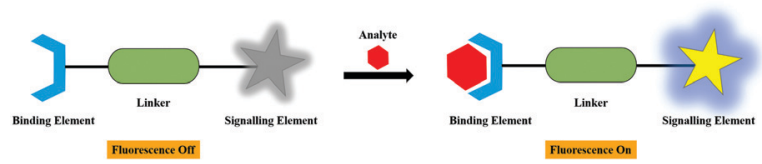

Fig. 1 The working principle of fluorescent chemosensor.

effective, economical, trouble-free process, and naked-eye detection. ${ }^{24-33}$

However, the design of fluorescent chemosensor for the most common binding and signalling approach required some of the crucial chemical components, which are predominantly obtained based on supramolecular chemistry principles for specific recognition in different media. Basically, the construction of a chemosensor involves the fusion of three basic units. They are the binding ionophore element, the signalling fluorophore element, and the linker or spacer for binding and signalling elements association, collectively called as "The Fluoroionophore or The Chemosensor", which detect several analytes such as metal cations, anions, neutral molecules, and small biological scaffolds. ${ }^{34-36}$ The design and the working principle of the fluorescent chemosensor is shown in Fig. 1.

\subsection{GO/rGO as fluorescent chemosensors}

The two-dimensional (2D) atomic crystals with $\mathrm{sp}^{2}$ hybridized carbons organized in a hexagonal framework are known as graphene nanomaterials and their family includes GO, rGO, and graphene quantum dots (GQD). ${ }^{37-39}$ In principle, the existence of oxygen-comprising functional groups displays visible and near-IR fluorescence characteristics to $\mathrm{GO}$ and rGO owing to the presence of a wide optical band gap by the implanted $\mathrm{sp}^{2}$ domains in the $\mathrm{sp}^{3}$ carbons rather than naked graphene with zero optical band gap, which exhibits no fluorescence. ${ }^{40-43}$ The optical properties including fluorescence emission and wavelength of the GO-based chemical sensors can be regulated by restraining the size of GO within few a nanometers and the chemical constitution. The electronic transitions between antibonding and bonding molecular orbitals such as $\sigma^{*} \rightarrow \mathrm{n}, \pi^{*} \rightarrow \mathrm{n}$, and $\pi^{*} \rightarrow \pi$ are the reason for the fluorescence in functionalized GO materials. ${ }^{44,45}$

The chemical reduction of oxygen-loaded functional groups such as carboxyls, alcohols, carbonyls, epoxides, and hydroxyls in GO appreciably accelerates the formation of electrically and thermally conductive rGO materials. ${ }^{46-48}$ These graphene-based nanomaterials as fluorescent chemosensors are being invented for the quick and sensitive recognition of the various types of analytes based on the strength of their remarkable characteristics, such as inexpensiveness, water-solubility, greater stability, high specific surface areas, biocompatibility, lower cytotoxicity, high electron mobilities, and extraordinarily low electronic noise. ${ }^{4-53}$ The chemically modulated and conjugated GO-based nanomaterials manifest efficient noncovalent interactions with the adsorbed molecules via supramolecular interactions such as hydrogen bonding, intramolecular $\pi-\pi$ interaction, and electrostatic attraction. Therefore, the tunable and intrinsic qualities of GO-based materials attract manifold applications in the discipline of fluorescent chemosensors as an outstanding fluorophore as well as a potential dual nature fluorescence quencher via charge transfer or resonance energy transfer processes. ${ }^{49,50,54-57}$

\subsection{Functionalizing materials}

Small molecules/nanoparticles-conjugated GO/rGO both by covalent and noncovalent interactions as nanocomposites have been demonstrated to be productive fluorescent chemical sensors for the detection of various target molecules. The molecules utilized for the functionalization of $\mathrm{GO} / \mathrm{rGO}$ are organic fluorophores, organic acids, polymers, organic dyes, inorganic nanoparticles, macrocyclic compounds, rotaxanes, DNA, metal oxides, chemodosimeter molecules, etc. In this review, we discuss extremely powerful functionalizing organic compounds and other materials with respect to BODIPY, coumarin, fluorescein, dextranfluorescein, 1,8-diaminenaphthalene, resorcinol, 8-hydroxyquinoline, pyrene, amino pyrene, terpyridine, 2-bis((pyridine-2ylmethyl)amino)ethan-1-ol, tris(2-aminoethyl)amine, bis-(pththalimidoethyl)-amine, $\gamma$-aminobutyric acid, azobenzoic acid, phenylboronic acid, oligo( $p$-phenylene ethynylene), labeled complementary oligonucleotides or aptamers, (polyvinylpyrrolidone)/ pyrene/APTS, polyethyleneimine, acridine orange, methylene blue, rhodamine $\mathrm{B}$, alizarin red, endonuclease, silver-specific cytosine rich oligonucleotide, mesoporous silica nanoparticles, carboxylated pillar[5] arene macrocycle, hematoporphyrin, RhBPy [2]rotaxane, molecular beacon, glycosyl, Ag-In-Zn-S (AIZS) quantum dots, DNAzymes, thymine, FAM, FAM-ssDNA, NiO, $\mathrm{TiO}_{2}$, and fluorescent chemodosimeter molecules.

These highly efficient GO/rGO-based hybrid fluorescent conjugates are synthesized by conventional methods such as grafting, electrospinning, solvothermal, covalent functionalization, chemical reflux, esterification, and reductive amination processes. $^{58-62}$ The synthesized sensor conjugates are the most attractive and can be employed for the recognition of several target molecules and ions on account of their favorable characteristics, such as simplicity and specificity, sharp absorption and fluorescence emission, high fluorescence quantum yields, low toxicity, highly stability, cost-effective, and good water solubility. ${ }^{49-53,56,57}$

To the best of our knowledge, this is the first and foremost review report discussing the fluorescent-functionalized GO/rGO nanomaterials for the detection of multifarious analytes. This review covers the general properties, synthesis, and utilization of $\mathrm{GO} / \mathrm{rGO}$-based fluorescent chemosensor conjugates for the sensitive and specific detection of various analytes such as metal cations $\mathrm{Ag}^{+}, \mathrm{Ce}^{3+}, \mathrm{Cu}^{2+}, \mathrm{Fe}^{2+}, \mathrm{Fe}^{3+}, \mathrm{Hg}^{2+}, \mathrm{Ni}^{2+}, \mathrm{Pb}^{2+}$, $\mathrm{Zn}^{2+}$, and $\mathrm{Zr}^{4+}$ ), anions $\left(\mathrm{F}^{-}\right.$and $\mathrm{I}^{-}$), amino acids (adenosine, cysteine, and lysine), carbohydrates (glucose), explosives (2,4,6trinitrotoluene and 2,4-dinitrotoluene), organic pollutants (bisphenol A, 1-naphthol, phenol, and picric acid), organic dyes (rhodamine 6G and neutral red), antibiotics (doxorubicin), RNA (miRNA), lectins, and viruses (Ebola) (Fig. 2). These nanosensor conjugates as host molecules express discriminative recognition and significant sensitivity toward various guest analytes with substantial selectivity and some even down to nanomolar level detection limits. In addition, this work highlights the challenges in GO/rGO-based fluorescent chemosensors and 


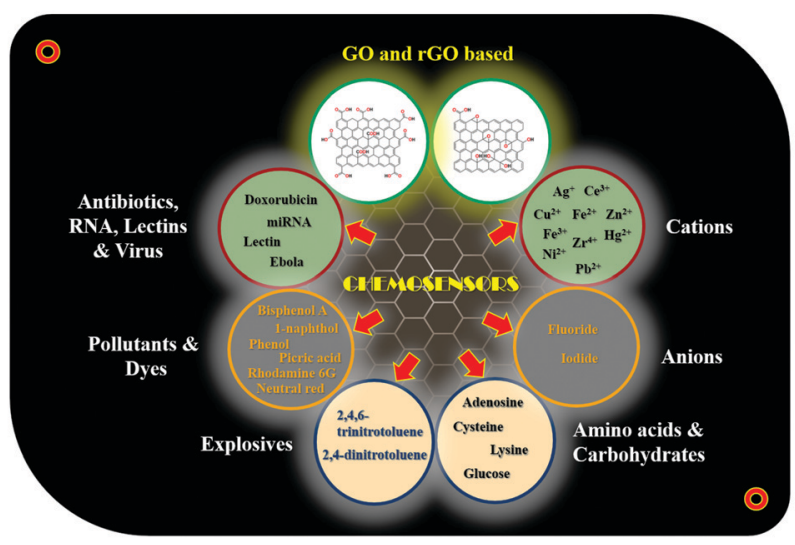

Fig. 2 The schematic representation of $\mathrm{GO} / \mathrm{rGO}$ derivatives in fluorescent analyte detection.

various potential applications in the wide spectrum of upcoming research areas.

\section{Fluorescence sensing strategy and mechanisms}

\subsection{Displacement strategy}

The nonfluorescent receptor-indicator system coordinated by noncovalent interactions separates into two components as the receptor-analyte framework upon the addition of a strong chelating analyte, which ultimately displace the indicator. Eventually, a significant transfiguration in the fluorescent signal was observed during the indicator displacement, leading to the formation of a noncoordinated state. The advantages of the displacement strategy are exchangeable indicators, independent analyte structure, easily tunable selectivity, reversibility, and specificity. These properties can be obtained because of the high flexibility rendered by the noncovalent linkage in the system. In this review, the displacement approach for the binding of different analytes with the functionalized GO/rGO nanomaterials has been discussed. The working principle of the displacement strategy is demonstrated in Fig. 3.

\subsection{Photoinduced electron transfer (PET)}

In the PET mechanistic process, generally, the ionophore unit is an electron donor and the fluorophore unit performs the role of an electron acceptor that are syndicated through the linker or the spacer moiety, which can be tuned. The fluorescence binding approach usually occurs between the electron donor

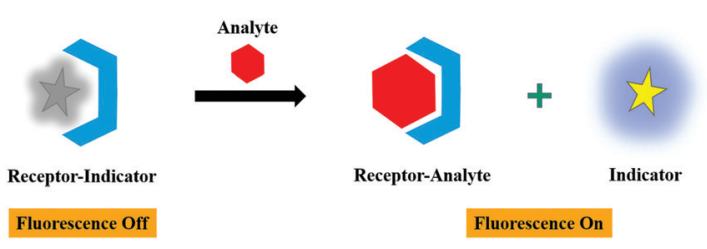

Fig. 3 The working principle of displacement strategy.

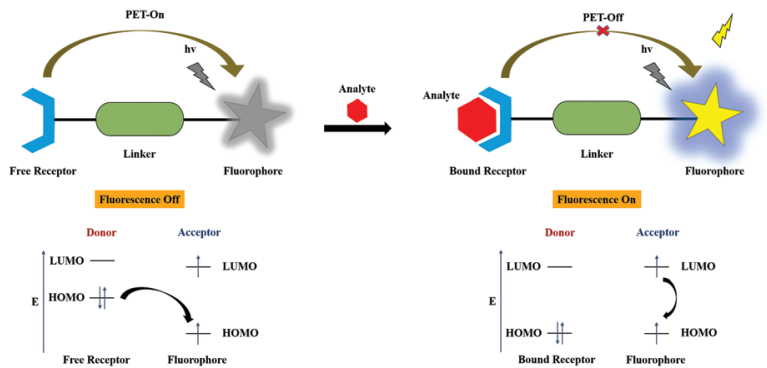

Fig. 4 The schematic illustration of the PET process.

and acceptor moieties, resulting in excited-state nonradiative radiation upon van der Waals interactions, revealing weak fluorescence. In the PET-On state, the excitation of the electron takes place from the highest occupied molecular orbital (HOMO) of the free receptor (ionophore) unit to the HOMO of the fluorophore unit, which can cause the quenching of fluorescence. The PET process is inhibited upon analyte binding due to interaction between the bound receptor and the analyte such that the electron transfer occurred from the lowest unoccupied molecular orbital (LUMO) to the HOMO in the fluorophore unit. In the course of binding, the redox potential of the free receptor HOMO is revived (lower energy) compared to the HOMO of the fluorophore unit; simultaneously, fluorescence enhancement is triggered and shows the PET-Off state. The schematic representation is shown in Fig. 4.

\subsection{Fluorescence resonance energy transfer (FRET or ET)}

The donor-fluorophore (DF) and acceptor-chromophore (AC) molecules are involved in distance-depeneant nonradiative energy transfer via the long-range dipole-dipole coupling mechanism. Upon electronic excitation, the donor can transfer its energy to a neighboring acceptor chromophore, leading to what is termed as the FRET process.

$$
\begin{gathered}
\mathrm{DF}+h v \rightarrow \mathrm{DF}^{*} \\
\mathrm{DF}^{*}+\mathrm{AC} \rightarrow \mathrm{DF}+\mathrm{AC}^{*} \\
\mathrm{AC}^{*} \rightarrow \mathrm{AC}+h v
\end{gathered}
$$

where $h$ is known as Planck's constant and $v$ is the radiation frequency.

During the process, there will be a decrease in the emission intensity of the donor fluorophore and an increase in the case of the acceptor chromophore, resulting in ratiometric fluorescence signals with an "isoemissive point". On the other hand, there will be null photonic emission perceived during the electronic excitation process of the system encompassing both the donor and acceptor molecules close to the emission maximum of the chromophore molecule. In FRET, the resonance energy of the acceptor is almost equivalent to the vibronic transitions of the donor and the Stokes' shift is increased artificially by the molecules. Nevertheless, spectral overlap is quite essential between acceptor absorption and 


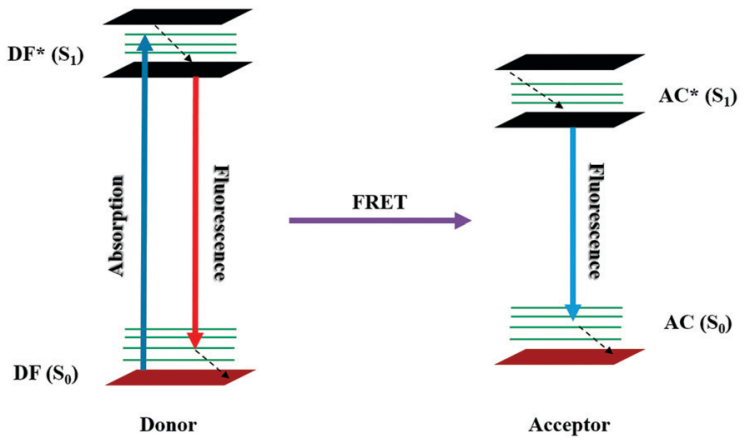

Fig. 5 The schematic illustration of the FRET process through a Jablonski diagram.

donor emission to achieve an efficient FRET process. The transitions involved in the FRET system are represented in Fig. 5.

\subsection{Intramolecular charge transfer (ICT)}

The wavelength-dependent absorption and emission color changes during the charge transfer process between the donor and acceptor moieties of the molecule is known as the photophysical process of ICT. The dipoles are formed when the charge transfer process takes place upon excitation from the donor to the acceptor of the system having almost equal electron densities. Thereby, the blue shift is distinguished in the spectrum on interaction of the electron donating moiety with an analyte, resulting in a decrease in electron donating character of the sensor. In contrast, while the electron acceptor moiety binds with an analyte, the electron accepting nature of the sensor increases, causing a red shift in the spectrum. Therefore, it is clear that the dipole strength varies upon analyte binding, which accounts for the photophysical changes in the system. The charge transfer process is also determined by the energy of transition and the type of solvent. The mechanism of the ICT process is illustrated in Fig. 6.

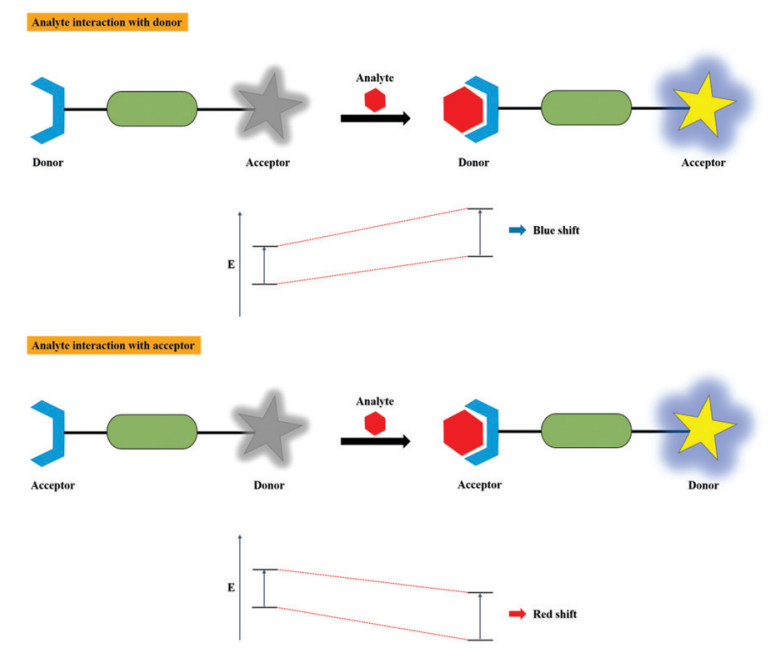

Fig. 6 The pictorial illustration of the ICT process.

\subsection{Excited state intramolecular proton transfer (ESIPT)}

The design of a fluorescent chemosensor via the ESIPT mechanism has absolute priority because of its distinctive photophysical properties and excellent sensitivity. As such, the ESIPT process prevails between the proton donating (amino or hydroxyl) and withdrawing groups (imine or carbonyl) upon excitation of a molecule via intramolecular hydrogen bond formation. The unusual keto-enol tautomeric transformation of the system from $\mathrm{E}$ to $\mathrm{K}$ via $\mathrm{E}^{*}$ and $\mathrm{K}^{*}$ will be affected on the interaction of the analyte, which radically diminishes the photochemical reactivity and enhances the photostability as well. The excited keto $\left(\mathrm{K}^{*}\right)$ formation from the excited enol $\left(\mathrm{E}^{*}\right)$ and stable keto $(\mathrm{K})$ to stable enol (E) transformation were induced at higher and lower emission wavelengths with larger Stokes' shift. The schematic representation of the ESIPT process is given in Fig. 7.

\subsection{Aggregation induced emission (AIE)}

An aggregated and highly photostable fluorescent solid possessing micro or nanochemical structures with luminescent property in aqueous media is more commonly known as an AIE active molecule. An AIE-based sensor is made up of a freely rotatable unit chained with a rigid core in the body, which emits weak fluorescence upon excitation. Nevertheless, it produces strong fluorescence emission upon aggregation by means of various interactions such as restriction of intramolecular vibration (RIV), $\pi-\pi$ stacking, restriction of intramolecular motion (RIM), twisted intramolecular charge transfer (TICT), and restriction of intramolecular rotation (RIR). Typically, the AIE phenomenon has been used for the characteristic understanding of AIE such as structural rotatability, planarity, intermolecular interactions, and intramolecular restrictions. Hence, the efficiency of the fluorescent aggregates in the presence of various analytes is largely ascribed to the restriction of intramolecular motion (RIM) and the restriction of intramolecular rotation (RIR) mechanisms. The graphical illustration of the AIE phenomenon is shown in Fig. 8.

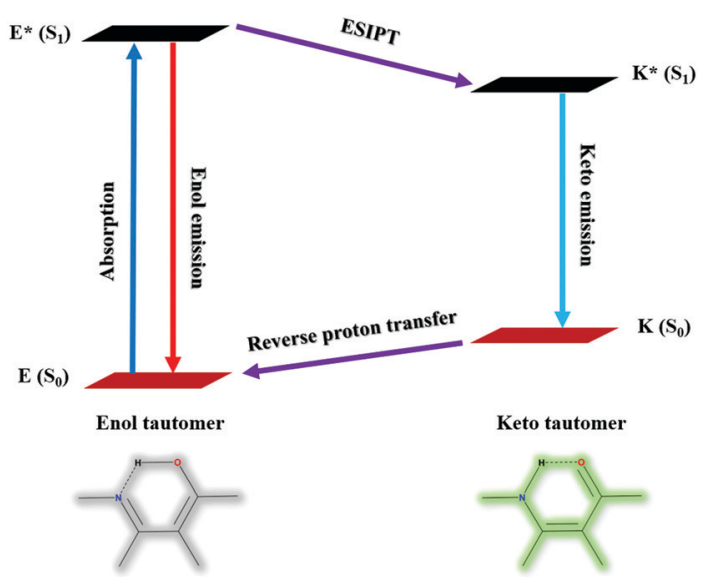

Fig. 7 The graphical representation of the ESIPT process. 

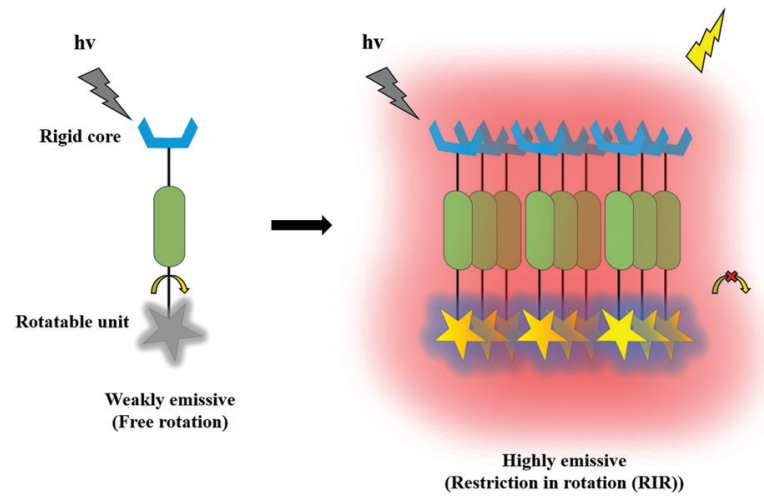

Fig. 8 The schematic illustration of the AIE phenomenon.

\section{Functionalized graphene oxide (GO) and reduced graphene oxide ( $\mathrm{rGO}$ )- based fluorescent chemosensors for various analytes' detection}

\subsection{Metal cations}

He et al. utilized a chemically modified GO derivative 1 (Fig. 9) for the specific detection of $\mathrm{Hg}^{2+}$ ion. It was synthesized using 4,4-difluoro-8-(4-isothiocyanatophenyl)-1,3,5,7-tetramethyl4-bora-3a,4a-diaza-s-indacene (BODIPY1) and characterized by FT-IR and atomic force microscopy (AFM). ${ }^{63}$ The synthesized organic-inorganic hybrid complex exhibited selective fluorescent turn-on response toward $\mathrm{Hg}^{2+}$ ion among various other heavy metal ions. The possible binding mechanism of $1+\mathrm{Hg}^{2+}$ was explained based on the suppression of two possible competitive processes, namely, PET and ET, due to the strong thiophilic affinity of the $\mathrm{Hg}^{2+}$ ion.

A highly selective and sensitive thymine-conjugated rGO chemosensor 2 was introduced by Abdelhamid's research group for the recognition of $\mathrm{Hg}^{2+}$ ion. ${ }^{64}$ The constructed system binds the $\mathrm{Hg}^{2+}$ ion with the thymine moiety through $\mathrm{T}-\mathrm{Hg}^{2+}-\mathrm{T}$ formation due to the electrostatic and $\pi-\pi$ interactions on the planar surface of rGO. Upon the addition of $\mathrm{Hg}^{2+}$, a drastic

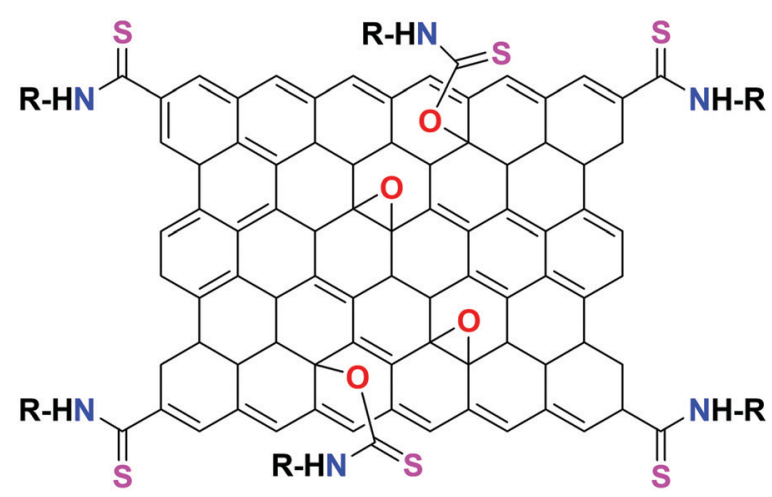

1

Fig. 9 The structure of chemosensor 1.

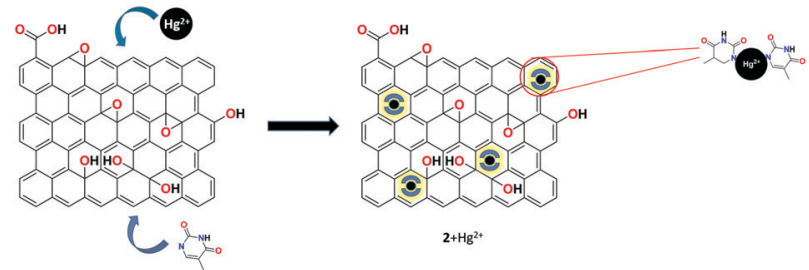

Fig. 10 The schematic representation of $\mathrm{Hg}^{2+}$ binding with the $\mathrm{rGO}$ conjugate.

fluorescence quenching was obtained compared to various other metal cations. This approach has produced a good detection limit of $5 \mathrm{nM}$ toward $\mathrm{Hg}^{2+}$ ion (Fig. 10).

Huang et al. demonstrated the bifunctional rGO-organic dye-based reversible fluorescence nanoswitch 3 for the sensitive and selective recognition of $\mathrm{Hg}^{2+}$ ions. ${ }^{65}$ Upon the binding of $\mathrm{Hg}^{2+}$ with receptor 3 , the organic dye acridine orange (AO) showed a remarkable fluorescence enhancement due to the adsorption of $\mathrm{Hg}^{2+}$ onto the rGO nanosheets, resulting in the removal of AO from the surface of rGO. The reformation of the rGO-AO nanocomplex caused the re-quenching of dye fluorescence upon the complexation of $\mathrm{Cys}-\mathrm{Hg}^{2+}$. Based on the selective binding and reversible property of receptor 3, the INHIBIT logical operation was carried out (Fig. 11).

An ultrasensitive fluorescent chemosensor 4 based on rhodamine B-associated $\mathrm{Ag} / \mathrm{rGO}$ nanocomposite was developed by Sahu et al. in aqueous media and the structural properties of this receptor were investigated by UV-Vis, FTIR, XRD, TEM, and SEM analyses. ${ }^{66}$ The presented system showed weak fluorescence through $\pi-\pi$ and dispersive interactions. Upon the interaction of $\mathrm{Hg}^{2+}$ ions with the rGO nanocomposite via soft-soft and $\pi$-metal interactions, high fluorescence emission was obtained. Therefore, it is clearly understood that the lowfluorescence material was broken into a highly fluorescent one upon the binding of $\mathrm{Hg}^{2+}$ and the displacement of rhodamine $\mathrm{B}$ from the $\mathrm{Ag} / \mathrm{rGO}$ nanoparticles was confirmed. The limit of detection of $\mathrm{Hg}^{2+}$ in aqueous solution was determined to be $2 \mathrm{nM}$ and the detection system was totally interference free from other co-existing metal ions (Fig. 12).

A facile FRET-based mesoporous silica nanoparticles functionalized with graphene oxide as the fluorescent chemosensor 5 was prepared by Zhang et al. for the detection of $\mathrm{Hg}^{2+}$ ions in aqueous solution. ${ }^{3}$ The receptor 5 was synthesized by grafting amine-modified fluorescent hybrid mesoporous silica nanoparticles containing poly( $p$-phenylenevinylene) and lactam

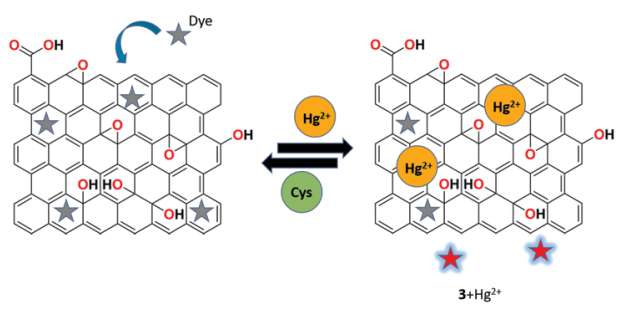

Fig. 11 The binding process of receptor 3 with $\mathrm{Hg}^{2+}$ ions. 


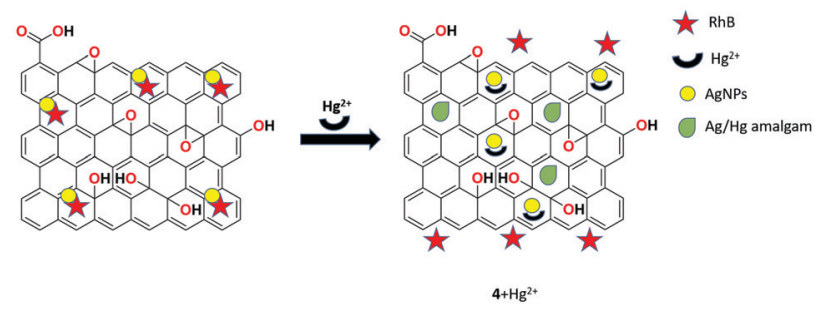

Fig. 12 Schematic representation of the binding process of $\mathrm{Hg}^{2+}$ ions with receptor 4

of rhodamine 6G with GO. This hybrid fluorescent receptor 5 exhibited strong green fluorescence and in the presence of $\mathrm{Hg}^{2+}$, the color changed to light orange and showed simultaneous ratiometric enhancement and quenching at $550 \mathrm{~nm}$ and $494 \mathrm{~nm}$, respectively. This selective detection was ascribed to the FRET process from the poly( $p$-phenylenevinylene) moiety to rhodamine, which was triggered upon the binding of $\mathrm{Hg}^{2+}$ ions with a detection limit of $7.1 \times 10^{-8} \mathrm{M}$ (Fig. 13).

Dinda et al. designed a new fluorescent turn off-on chemosensor 6 based on thymine-functionalized GO for the simultaneous recognition of $\mathrm{Hg}^{2+}$ and $\mathrm{I}^{-}$ions in aqueous medium. ${ }^{67}$ The mercury ion selectively quenched the receptor's fluorescence, which is ascribed to the PET process and upon the addition of $\mathrm{I}^{-}$ions, the fluorescence was recovered and a stable $\mathrm{HgI}_{2}$ complex was formed due to the blocking of PET from the electron-rich fluorophore to the electron-deficient $\mathrm{Hg}^{2+}$ ions. These specific detections are free of interference from other co-existing metal ions at nanomolar concentrations. The quenching and enhancement mechanisms were studied in detail using density functional theory (DFT) calculations.

A novel coumarin-rGO-based fluorescent turn-on receptor 7 was proposed by Akhila et al. for the selective detection of $\mathrm{Cu}^{2+}$ ions in aqueous solution over other competing metal ions. ${ }^{68}$ The fluorescence intensity of receptor 7 was restored upon the addition of $\mathrm{Cu}^{2+}$ with outstanding sensitivity and selectivity. In addition, the complexation was clearly verified using the strong chelating agent EDTA, which also confirmed a very low limit of detection ( $2 \mathrm{fM}$ ) toward copper ions compared with several previously reported complexing systems (Fig. 14).

Awad et al. reported a highly sensitive and selective $\mathrm{Cu}^{2+}$ ion fluorescent chemosensor 8 based on hematoporphyrinfunctionalized GO synthesized via the esterification reaction and confirmed by the FTIR, XRD, SEM, UV-Vis, TEM, XPS, and

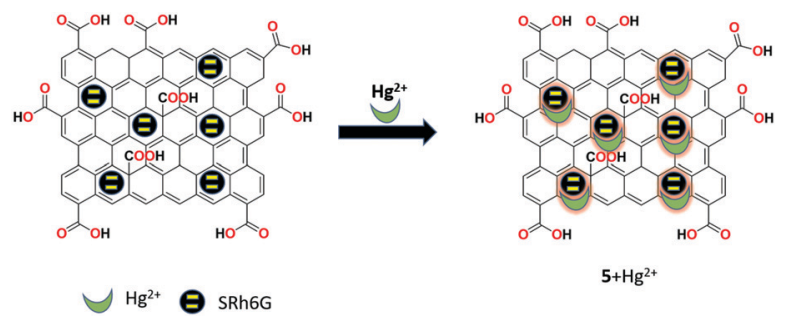

Fig. 13 The selective binding of receptor 5 with $\mathrm{Hg}^{2+}$ ions through the FRET process.

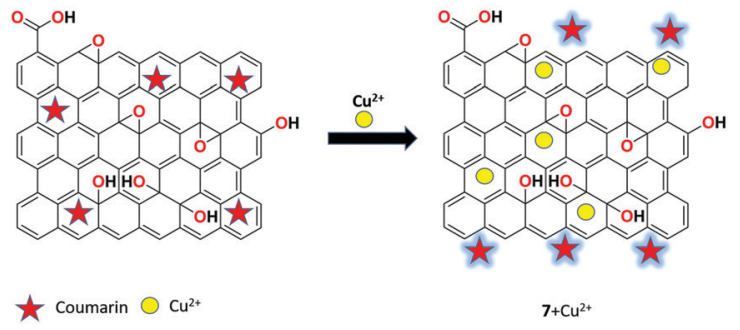

Fig. 14 The proposed sensing mechanism of fluorescent sensor 7 for $\mathrm{Cu}^{2+}$ detection.

Raman spectroscopic techniques. ${ }^{69}$ The receptor 8 exhibited high selectivity toward $\mathrm{Cu}^{2+}$ ion over other metal ions due to the presence of the aza macrocyclic ring on the surface, which has high binding affinity with copper ions. The receptor 8 showed a detection limit of $54 \mathrm{nM}$, which is lower than that in many other reported studies (Fig. 15).

Huang et al. used a turn-on fluorescent strategy for the recognition of $\mathrm{Cu}^{2+}$ ions by a molecular beacon and GO-based fluorescent biosensor 9 in the Tris-HCl buffer solution at $\mathrm{pH}$ 8.0. ${ }^{70} \mathrm{GO}$ acts as a fluorescence quencher upon the adsorption of the recognition unit molecular beacon (MB) and the system is highly sensitive toward cations. In the presence of $\mathrm{Cu}^{2+}$ ions, the MBs were cleaved into pieces from the GO surface and produced strong fluorescence signals with the detection limit of $53.3 \mathrm{nM}$. The recognition quality of the receptor was not affected by the other interfering metal ions. Furthermore, sensor 9 was utilized in real sample analysis for the detection of $\mathrm{Cu}^{2+}$ ions with satisfactory results (Fig. 16).

Li et al. prepared a fluorescent nanoprobe 10 by grafting $\gamma$-aminobutyric acid (GABA) on GO and characterized it by XPS, FTIR, and UV-Vis analyses. The synthesized fluorescent nanoprobe 10 was used as a highly sensitive and specific GO-based fluorescent sensor for the relay recognition of $\mathrm{Cu}^{2+}$ ions and cysteine. ${ }^{71}$ Sensor 10 produced static fluorescence quenching selectively upon the addition of $\mathrm{Cu}^{2+}$ ions and sequentially recognized cysteine (Cys) with strong fluorescence enhancement. Sensor 10 showed a detection limit of $15 \mathrm{nM}$ for $\mathrm{Cu}^{2+}$ ions and $38 \mathrm{nM}$ for Cys. In addition, low cytotoxicity was obtained for the

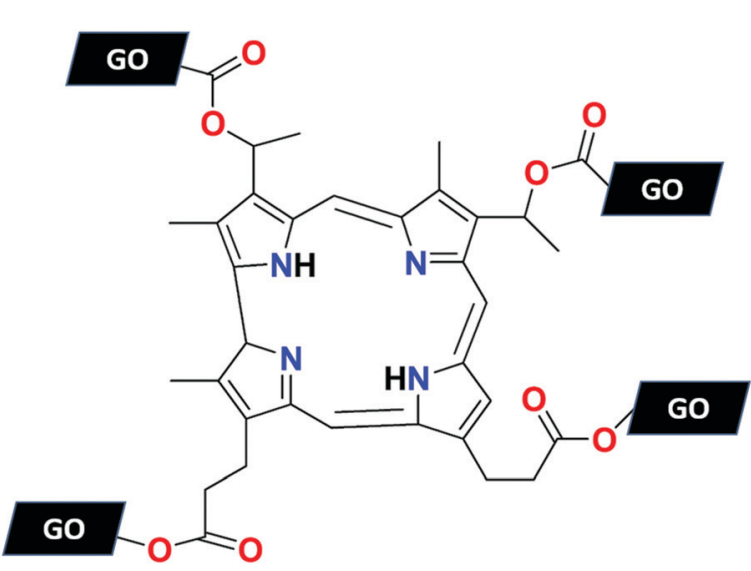

Fig. 15 The structure of receptor $\mathbf{8}$. 

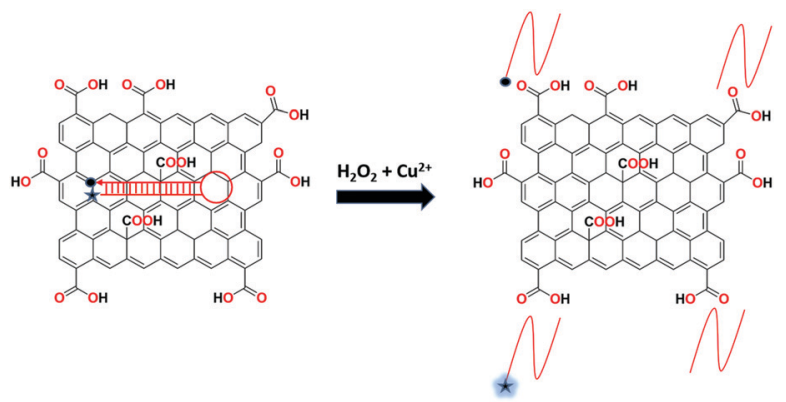

Fig. 16 The sensing process of receptor 9 toward $\mathrm{Cu}^{2+}$ ions.

receptor and was applied successfully in LLC-PK1 cells for $\mathrm{Cu}^{2+}$ and Cys relay recognition.

GO-modified Ag-In-Zn-S (AIZS) quantum dots as fluorescent receptor 11 was designed by Liu et al. for the specific detection of $\mathrm{Cu}^{2+}$ ions. ${ }^{72}$ Upon the addition of $\mathrm{Cu}^{2+}$, the carboxylate-copper complex was formed in the form of R-COO- $\left(\mathrm{Cu}^{2+}\right)-\mathrm{OOC}-\mathrm{R}$, which exhibits quenching of fluorescence and was characterized by TEM and FTIR analyses. Specific $\mathrm{Cu}^{2+}$ sensing was not further influenced by any other metal ions at $\mathrm{pH}$ 7.4. The limit of detection was calculated to be $0.18 \mu \mathrm{M}$ and $R^{2}=0.99$. The results revealed that sensor 11 could be serve as an effective probe in the determination of $\mathrm{Cu}^{2+}$ ion in drinking water samples.

The research group of Cheng introduced a simple highly selective and sensitive GO-1,8-DAN (1,8-diaminenaphthalene) conjugate-based fluorescent receptor 12 for the detection of $\mathrm{Ag}^{+}$ ions. ${ }^{73}$ Based on the well-established method of EDC/NHS coupling chemistry, the sensor was synthesized by incorporating 1,8-DAN on the surface of GO (Fig. 17). The synthesized receptor 12 showed low fluorescence emission due to the PET process and subsequently exhibited dual-output of enhanced fluorescent signal at $589 \mathrm{~nm}$ and quenched the fluorescent signal at $392 \mathrm{~nm}$, which was attributed to the second order scattering (SOS) process upon binding with $\mathrm{Ag}^{+}$ions.

Goldooz et al. described a highly specific $\mathrm{Ag}^{+}$ion chemosensor 13 based on 8-hydroxyquinoline-functionalized GOsilica nanocomposite (Fig. 18) in aqueous media. ${ }^{74}$ The nanocomposite fluorescent receptor was synthesized by grafting the

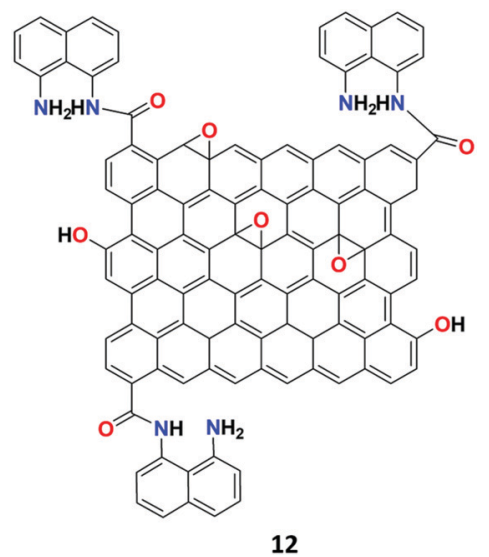

Fig. 17 The structure of receptor 12 .

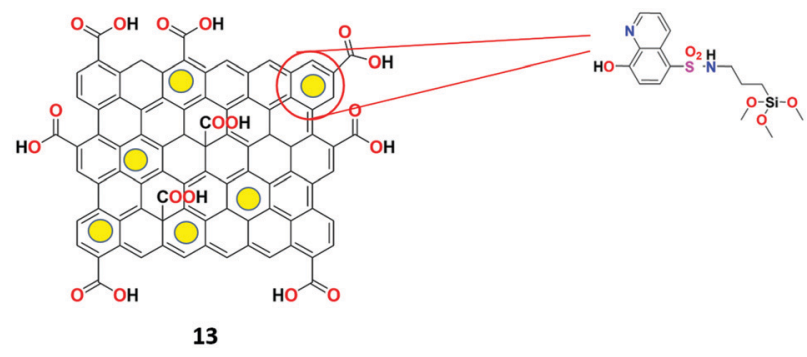

Fig. 18 The structure of receptor 13 .

aminopropyl group using APTES on the graphene-mesoporous silica composite and then the surface was reacted with 8-hydroxyquinoline- $\mathrm{SO}_{2} \mathrm{Cl}$ to obtain receptor 13 . Surprisingly, the receptor exhibited appreciable second-order scattering signals specifically for $\mathrm{Ag}^{+}$ions at $720 \mathrm{~nm}$ and $483 \mathrm{~nm}$ in the presence of various metal ions. The limit of detection of receptor 13 for $\mathrm{Ag}^{+}$was determined to be $6.57 \times 10^{-6} \mathrm{M}$ and the obtained spectral results were used for the construction of a combinatorial logic circuit.

Bhuvanesh and his co-workers developed a chemosensor by the hydrothermal method, and rGO-functionalized with organic compound (S)-1 was used as fluorescent chemosensor 14 for the selective detection of $\mathrm{Ag}^{+}$ions in the aqueous solution at the physiological $\mathrm{pH}$ range. ${ }^{75}$ The synthesized fluorescent nanocomposite was characterized by various techniques such as spectroscopic, microscopic, and analytical techniques. Interestingly, sensor 14 shows significant enhancement $\mathrm{Of} \mathrm{Ag}^{+}$with no observable interference from other common metal ions at room temperature (Fig. 19).

Wen et al. reported a graphene oxide and silver-specific cytosine-rich oligonucleotide (SSO)-based $\mathrm{mix}$ and detect fluorescent nanoreceptor 15 for the selective detection of silver ions. ${ }^{76}$ The interaction between the target-induced conformational change of unbound SSO with GO causes the quenching effects. Upon the addition of silver ions, the fluorescence was retained and a quantitative readout was obtained. Therefore, the results clearly demonstrate the simple DNA-based strategy for the detection of various and multiple targets (Fig. 20).

A reversible probe-GO based fluorescent chemosensor 16 was prepared by $\mathrm{Lv}$ et al. for the recognition of $\mathrm{Ag}^{+}$and $\mathrm{I}^{-}$ ions. ${ }^{77}$ By mixing FAM-ssDNA with GO, the receptor was synthesized. FAM-ssDNA was brought into close proximity with the surface of the GO sheet due to the $\pi$-stacking interactions. The free receptor 16 showed weak fluorescence and upon the

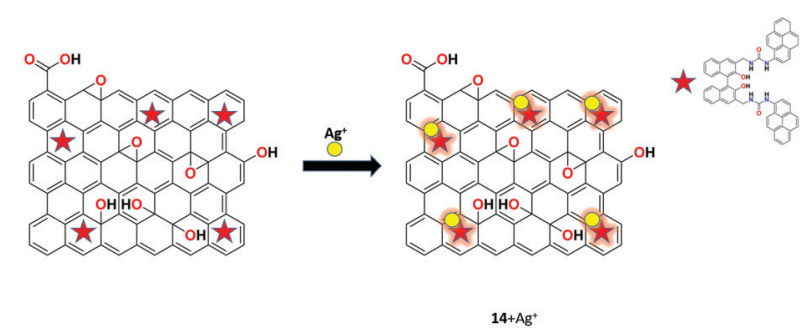

Fig. 19 The binding phenomena of receptor 14 with $\mathrm{Ag}^{+}$ions. 


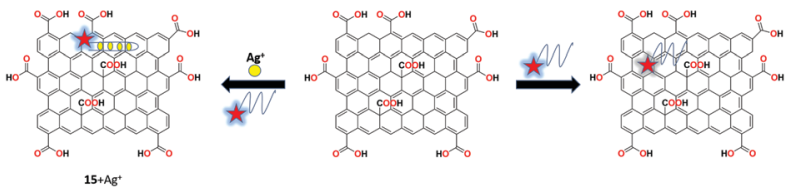

Fig. 20 The mix and detect strategy for the detection of $\mathrm{Ag}^{+}$ions using receptor 15 .

addition of $\mathrm{Ag}^{+}$ions, fluorescence emission was recovered. Consequently, on the continuous addition of iodide into the above system, AgI was formed and fluorescence was regained. This off-on-off multifunctional analysis upon the sequential addition of $\mathrm{Ag}^{+}$and $\mathrm{I}^{-}$was used to construct the INHIBIT logic gate based on the reversible probe-GO receptor. The detection limits were determined to be $10 \mathrm{nM}$ and $50 \mathrm{nM}$ for $\mathrm{Ag}^{+}$and $\mathrm{I}^{-}$ ions, respectively. In addition, the sensing studies were carried out in water and human urine samples with satisfactory results (Fig. 21).

Pandiyarajan's group demonstrated a $\mathrm{TiO}_{2}$-decorated GObased nanocomposite as the fluorescent chemosensor 17 for the discriminative recognition of $\mathrm{Ag}^{+}$ions in $\mathrm{THF}-\mathrm{H}_{2} \mathrm{O}$ $(1: 1, \mathrm{v} / \mathrm{v})$ solution. ${ }^{78}$ Receptor 17 was synthesized by the chemical reflux method and characterized using SEM, $\mathrm{XRD}$, and UV-Vis analyses. The resulting nanocomposite 17 specifically recognized $\mathrm{Ag}^{+}$ions in the physiological $\mathrm{pH}$ range without the interference of other potentially interfering metal ions. Upon the addition of $\mathrm{Ag}^{+}$ion with receptor 17, the strong fluorescence monitored was attributed to the inhibition of the PET process.

A new hybrid GO-resorcinol composite as the reversible fluorescent chemosensor 18 was developed by Dmonte et al. capable of specifically recognizing $\mathrm{Ce}^{3+}$ ions in the THF- $\mathrm{H}_{2} \mathrm{O}$ $(1: 1 \mathrm{v} / \mathrm{v})$ solution with no interference of other co-existing metal ions. ${ }^{79}$ The sensor was synthesized using modified Hummers' method and characterized by SEM, XRD, FT-IR, and UV-Vis analyses. The sensor produced weak fluorescence initially and exhibited significantly stronger fluorescence upon the addition of $\mathrm{Ce}^{3+}$ ions with a red shift from $306 \mathrm{~nm}$ to $351 \mathrm{~nm}$. The plausible sensing mechanism of the fluorescence "off-on" approach is the reason behind the occurrence of PET and ICT processes (Fig. 22).

Recently, Dmonte et al. introduced a hybrid nanomaterial using reduced graphene oxide and resorcinol (rGO-R) for the specific recognition of cerium ions. ${ }^{80}$ The synthesized nanocomposite was confirmed by XRD and SEM, and their optical properties were examined through UV-visible spectroscopy and

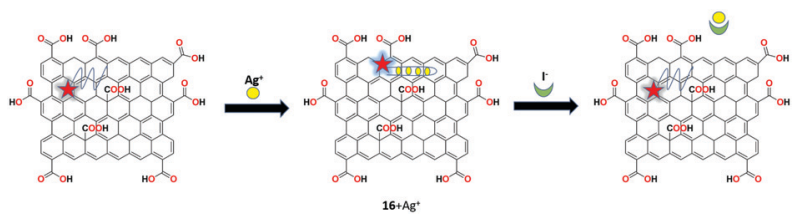

Fig. 21 The fluorescent binding response of receptor 16 with $\mathrm{Ag}^{+}$and Iions.

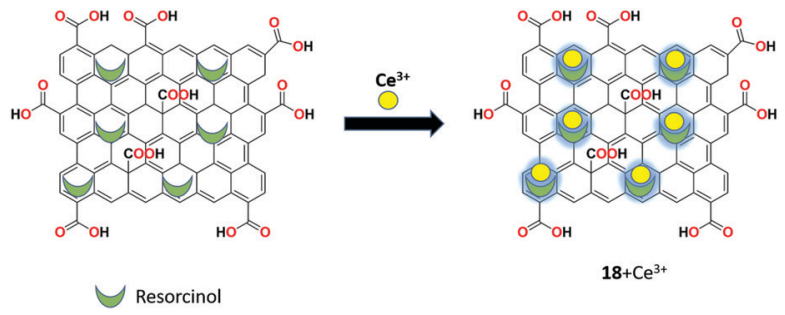

Fig. 22 The proposed binding mechanism of receptor 18 with $\mathrm{Ce}^{3+}$ ions.

photoluminescence studies. The fluorescent recognition process was carried out in $\mathrm{THF}-\mathrm{H}_{2} \mathrm{O}$ solution at a physiological $\mathrm{pH}$ of 7.4. The selective detection of cerium ions by the receptor rGO-R is attributed to the arrest of the PET process and ICT process, which eventually led to a noteworthy bathochromic shift to $351 \mathrm{~nm}$ from $306 \mathrm{~nm}$.

Elsie et al. used covalently modified GO as a reversible fluorescent chemosensor 19 for the detection of $\mathrm{Ce}^{3+}$ ion. ${ }^{81}$ The sensor was synthesized using the covalent functionalization of tris(2-aminoethyl)amine on the surface of graphene oxide by the ring opening of epoxide with primary amine moieties. This intercalated material was characterized by IR, XPS, SEM, XRD, and UV-Vis spectral analyses. Receptor 19 showed significant fluorescent enhancement upon the addition of $\mathrm{Ce}^{3+}$ ion, indicating the possible PET and ICT processes between GO and intercalated amine. Furthermore, receptor 19 could be effectively retained from its $\mathrm{Ce}^{3+}$ complex by the addition of the strong complexing agent EDTA in THF- $\mathrm{H}_{2} \mathrm{O}(1: 1, \mathrm{v} / \mathrm{v})$ solution (Fig. 23).

Shi et al. investigated an amino pyrene (AP)-grafted graphene-based gold nanoparticles as fluorescent receptor 20 for the recognition of $\mathrm{Pb}^{2+}$ ions with fluorescence "turn-on" response. ${ }^{82}$ The system exhibited the quenching of fluorescence in the presence of GO with AP due to the $\pi-\pi$ stacking interactions. The obtained stronger fluorescence showed the effective binding of $\mathrm{Pb}^{2+}$ ion in the presence of thiosulfate with receptor 20 by the mix and detect method. Under the optimal conditions, the sensing system showed a low detection limit of $0.1 \mathrm{nM}$ within the analytical time of about $15 \mathrm{~min}$. In addition, receptor 20 showed satisfactory recovery results for real water samples over other possible interferants (Fig. 24).

A novel fluorescent chemosensor 21 based on DNAzymescoupled multi-cycle strand displacement amplification (M-SDA) and GO (Fig. 25) was presented by Chen et al. for the ultrasensitive recognition of lead $\left(\mathrm{Pb}^{2+}\right)$ ions. ${ }^{83}$ Sensor 21 showed

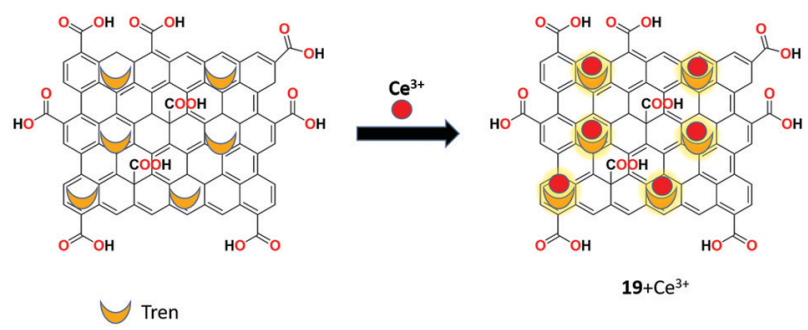

Fig. 23 The schematic illustration of the binding process of $\mathrm{Ce}^{3+}$ with receptor 19. 


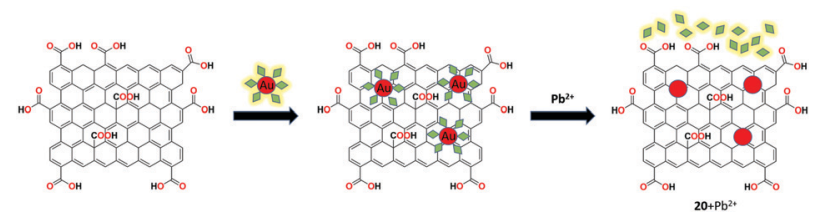

Fig. 24 The pictorial representation of the binding of $\mathrm{Pb}^{2+}$ ions with receptor 20 .

high amplification efficiency and outstanding specificity toward the metal ions owing to the high selectivity of DNAzymes. Under the optimal experimental conditions, fluorescent sensing studies were carried out with various metal ions, which revealed that the sensor specifically showed strong fluorescence of the $\mathrm{Pb}^{2+}$ ions among other interfering metal ions. The sensor 21 achieved good linearity $\left(R^{2}=0.99714\right)$ toward $\mathrm{Pb}^{2+}$ ion with the detection limit of $6.7 \mathrm{pM}$.

Senol et al. utilized fluorescein and polyethyleneimine (PEI)functionalized rGO-based fluorescent receptor 22 for the turn off-on detection of $\mathrm{Fe}^{3+}$ ions in aqueous medium. ${ }^{84}$ The nanocomposite receptor was synthesized by a facile and controllable method. Afterward, it was characterized by XRD, FTIR, UV-Vis, DLS, Raman spectroscopy, and zeta potential measurements. The fluorescence responses reveal that the system exhibits high sensitivity toward $\mathrm{Fe}^{3+}$ ions with the detection limit of $1.12 \mu \mathrm{M}$ and the receptor was reversible upon the addition of the strong chelating agent EDTA. This turn offon fluorescent response of the system provides promising characteristics such as quick response, nontoxicity, and low cost compared to other detection systems (Fig. 26).

Belinda Asha et al. constructed a covalent-modified GO-based carbonaceous material as the highly fluorescent chemosensor 23 for the specific recognition of $\mathrm{Zr}^{4+}$ ions in aqueous solution. ${ }^{85}$ The sensor was prepared by functionalizing GO with 2-bis((pyridine-2-ylmethyl)amino)ethan-1-ol (PAE) and characterized by various analytical techniques. Covalent bond formation between GO and PAE through the ester linkage was supported by all the characterization techniques. The fluorescence response of receptor 23 upon testing with a series of metal ions showed that $\mathrm{Zr}^{4+}$ ion selectively binds with receptor 23 and delivered the turn-on response via the FRET mechanism. The system offered a low limit of detection for $\mathrm{Zr}^{4+}$ of $27 \mathrm{ng} \mathrm{mL}{ }^{-1}$ in the aqueous medium (Fig. 27).

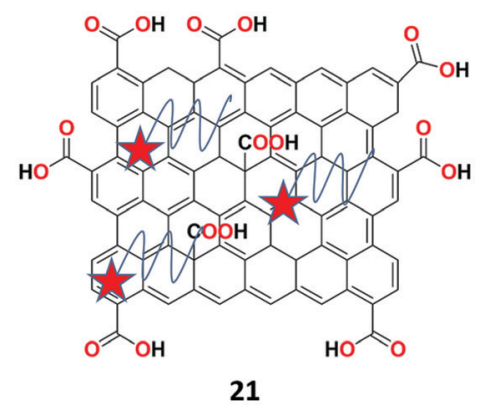

Fig. 25 The structure of receptor 21.

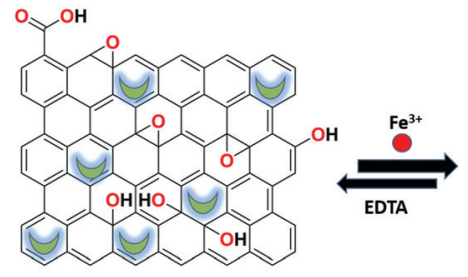

Fluorescein

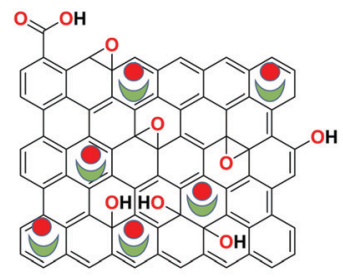

$22+\mathrm{Fe}^{3+}$

Fig. 26 The process of $\mathrm{Fe}^{3+}$ detection by receptor 22.

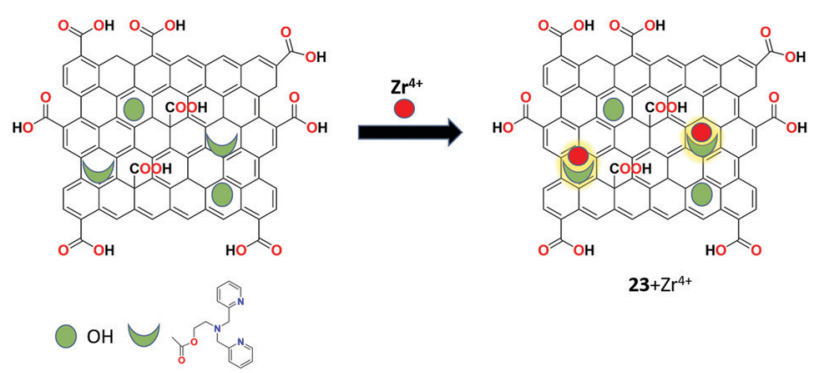

Fig. 27 The complexation strategy of receptor 23 with $\mathrm{Zr}^{4+}$.

The nonosensor 24 was synthesized by Eftekhari-Sis and co-workers based on 8-hydroxyquinoline-functionalized GO (Fig. 28) in aqueous media for the selective detection of $\mathrm{Zn}^{2+}$ ions. ${ }^{86}$ The nanosheet structure of receptor 24 was confirmed by FT-IR, UV-Vis, SEM, TEM, XRD, and EDX analyses. In the fluorescence spectra, receptor 24 showed weak fluorescence emission due to the ESIPT process in the 8-hydroxyquinoline molecule and upon chelating with $\mathrm{Zn}^{2+}$, the ESIPT process was prohibited and the fluorescence become stronger. In addition, the competitive experimental results revealed that the receptor shows good binding ability toward $\mathrm{Zn}^{2+}$ ions in the presence of most other metal ions.

Eftekhari-Sis et al. described GO and terpyridine conjugate as a highly specific fluorescent nano-chemosensor 25 (Fig. 29) for the recognition of $\mathrm{Fe}^{2+}$ ions in aqueous medium. ${ }^{87}$ The synthesized receptor 25 was characterized by FTIR, SEM, TEM, and UV-vis analyses. Surprisingly, the receptor displayed

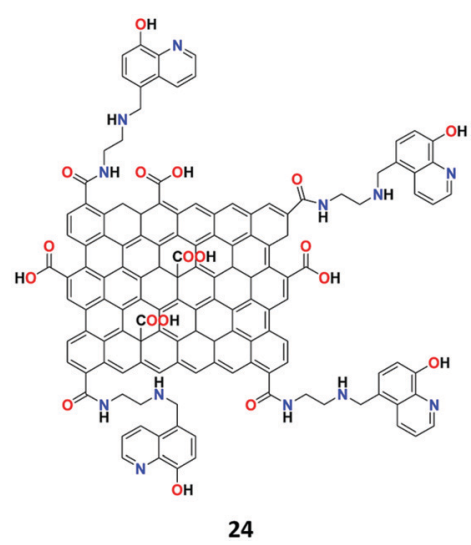

Fig. 28 The structure of receptor 24 . 


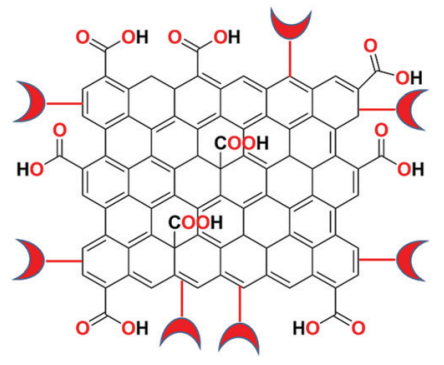

25

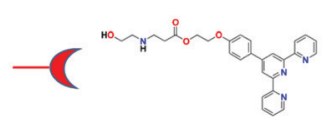

Fig. 29 The structure of receptor 25

colorimetric turn-on and fluorometric turn-off responses toward $\mathrm{Fe}^{2+}$ ions at $568 \mathrm{~nm}$ and $473 \mathrm{~nm}$, respectively. The naked-eye color changes were observed from light pink to deep magenta for $\mathrm{Fe}^{2+}$ ions via paper strip analysis.

Bis(pththalimidoethyl)-amine-functionalized GO as a highly efficient fluorescent chemosensor 26 was presented by the group of Ramesh for the recognition of $\mathrm{Ni}^{2+}$ ion in aqueous solution in the neutral $\mathrm{pH}$ range. ${ }^{88}$ The sensor was prepared using the masked triethylamine derivative as an intercalating agent on the surface of GO and was characterized by XRD, XPS, FTIR, TGA, Raman spectroscopy, and TEM analyses. In fluorescence spectroscopy, the nanocomposite exhibited selective response toward $\mathrm{Ni}^{2+}$ ion compared to other commonly interfering metal ions in aqueous solution at room temperature (Fig. 30).

\subsection{Anions}

A GO-assisted fluorescent chemodosimeter 27 was performed by Wang et al. for the efficient detection of fluoride $\left(\mathrm{F}^{-}\right)$ions. ${ }^{89}$ The GO-assisted fluorescent chemodosimeter 27 showed excellent sensitivity toward $\mathrm{F}^{-}$ions with 5 -fold higher reaction rate constant compared to the simple fluorescent chemodosimeter molecule. Owing to the nanocarrier function of GO, receptor 27 showed better bioimaging results on the addition of $\mathrm{F}^{-}$ions. Furthermore, the detection response of receptor 27 toward $\mathrm{F}^{-}$ions was applied successfully in real water sample analysis (Fig. 31).

\subsection{Amino acids and carbohydrates}

Adachi's group investigated an oligo( $p$-phenylene ethynyleneOPE)-GO composite 28 (Fig. 32) for the purpose of selective

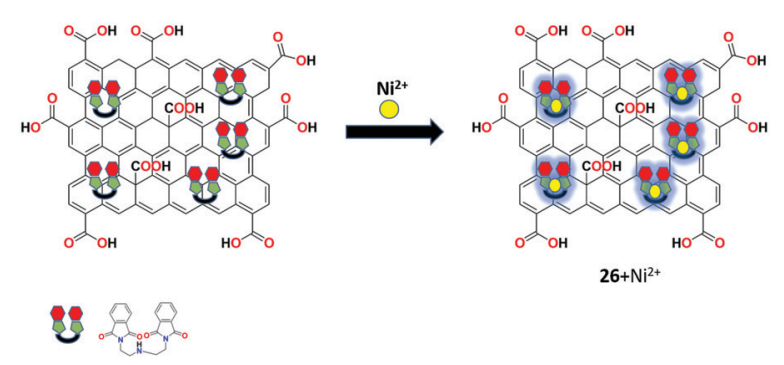

Fig. 30 The complexation strategy of receptor 26 with $\mathrm{Ni}^{2+}$ ions.

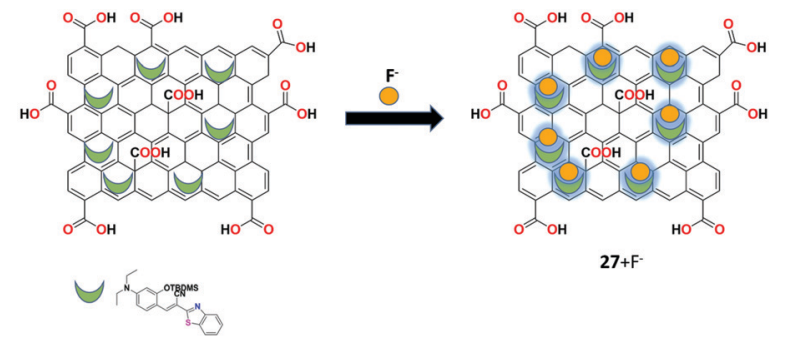

Fig. 31 The fluorescent sensing performance of receptor $\mathbf{2 7}$ with $\mathrm{F}^{-}$ions.

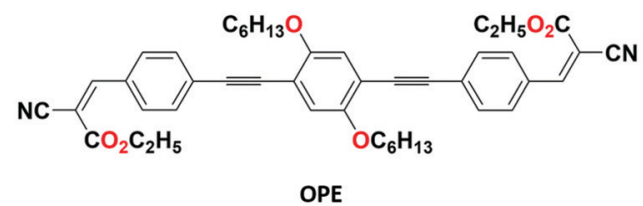

Fig. 32 The structure of OPE.

recognition of cysteine (Cys) in $\mathrm{THF}-\mathrm{H}_{2} \mathrm{O}(1: 1, \mathrm{v} / \mathrm{v})$ medium. ${ }^{90}$ The organic group (OPE) was synthesized with the help of Sonogashira coupling reaction and Knoevenagel condensation. Both the chemosensors, the simple organic moiety (OPE) with cyanoacrylate terminal groups and OPE-GO 28, show selective recognition toward cysteine (Cys) by exhibiting fluorescence turn-off and turn-on responses, respectively. The binding of cysteine is attributed to the blocking of the PET mechanism.

Bai et al. designed a simple mix-and-detect fluorescent turnon aptasensor 29 for the recognition of adenosine molecule. ${ }^{91}$ The GO-aptamer sensor was designed based on the targetinduced two-split aptamer sequences (ABA1-FAM: 5'-FAM-ACC TGG GGG AGT AT-3' and ABA2: 5'-TGC GGA GGA AGG T- $3^{\prime}$ ) and forms stable complexes in the aqueous solution due to the $\pi-\pi$ stacking interactions between the GO honeycomb lattices and the nucleotide bases. The prominent advantages of sensor 29 are simple and cost-effective detection and fluorescent background quenching upon the binding of the fluorophore with GO, which eventually creates a new universal platform for specific recognition by means of split aptamer engineering technology.

Blessy Pricilla et al. prepared the GO/NiO nanocomposite as fluorescent receptor 30 for the potential detection of L-leucine molecule without the interference of other competing amino acids in aqueous media. ${ }^{92}$ Receptor 30 was synthesized using the solvothermal method and it showed very weak fluorescence at $410 \mathrm{~nm}$; however, upon the addition of L-leucine to the receptor, noticeable fluorescent enhancement was observed with the turn-on process through the suppression of the PET mechanistic process. In addition, receptor 30 showed better antibacterial properties against methicillin resistant Staphylococcus aureus and A. baumannii (Fig. 33).

A highly sensitive and remarkably selective fluorescent nanocomposite based on graphene oxide-copper oxide material (GO-CuO) was reported by Blessy Pricilla et al. for the detection of one of the naturally-occurring amino acids, L-leucine. ${ }^{93}$ The fluorescent nanocomposite GO-CuO showed the selective 


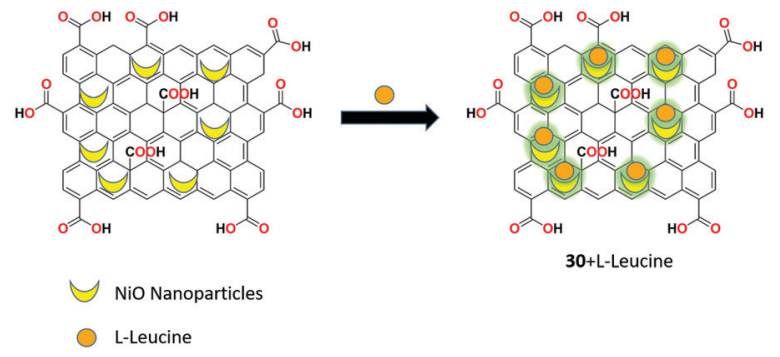

Fig. 33 The binding strategy of receptor $\mathbf{3 0}$ with L-leucine.

detection of L-leucine in the presence of different naturally occurring L-amino acids without any interferences. The receptor exhibited "turn-on" fluorescence response upon the addition of $\mathrm{L}^{-}$ leucine due to the inhibition of the PET process. In addition, the fluorescent property of the sensor was examined by conducting various studies on the effect of equivalence, time, and $\mathrm{pH}$ on the fluorescence in aqueous medium.

The fluorescent detection of lysine molecule using alizarin red-aluminium(III) complex-conjugated GO nanomaterial 31 was introduced by Cheng et al. as a turn-on receptor. ${ }^{94}$ The free receptor 31 showed weak fluorescence at $512 \mathrm{~nm}$ and significantly exhibited strong fluorescence upon the addition of lysine through the PET process with the detection limit of $2 \mathrm{mg} \mathrm{L}^{-1}$ in the $\mathrm{pH}$ range of 6.2 to 7.2. The selective binding strategy was also applied for the bioimaging application in human retinal pigment epithelium (ARPE-19) cells (Fig. 34).

In 2016, Basiruddin et al. constructed a phenylboronic acidfunctionalized rGO and di-ol-modified fluorescent chemosensor 32 for glucose detection in aqueous medium. ${ }^{95}$ Chemosensor 32 was synthesized by conjugating 3 -aminophenylboronic acid and the fluorescence molecule (5-(2-amino-ethylamino)-naphthalene1-sulphonuc acid) with rGO using the reductive amination method. Upon the addition of the glucose molecule, the sensor produces fluorescence from the quenching state because of the replacement of the di-ol-modified fluorescent probe by the glucose moiety. Sensor 32 could be potentially used in the concentration range of $2 \mathrm{mg} \mathrm{mL}^{-1}$ to $75 \mathrm{mg} \mathrm{mL}^{-1}$ using this nonenzymatic and cost-effective approach (Fig. 35).

\subsection{Explosives}

Guo and co-workers presented novel (polyvinylpyrrolidone)/ pyrene/APTS/rGO fluorescent nanonets 33 (Fig. 36) based on

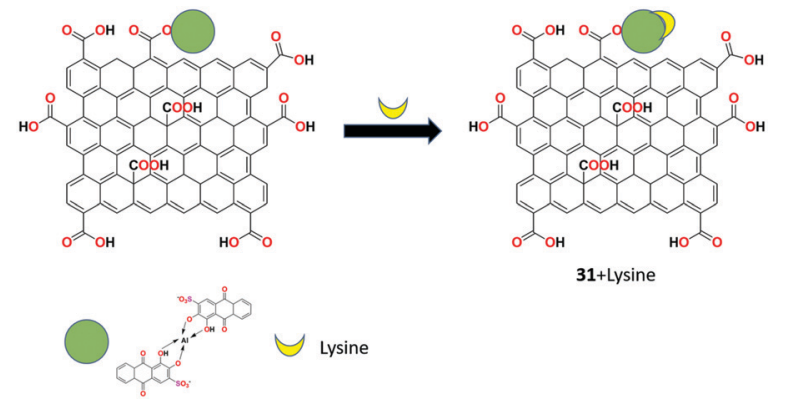

Fig. 34 The binding strategy of receptor 31 with the lysine molecule.

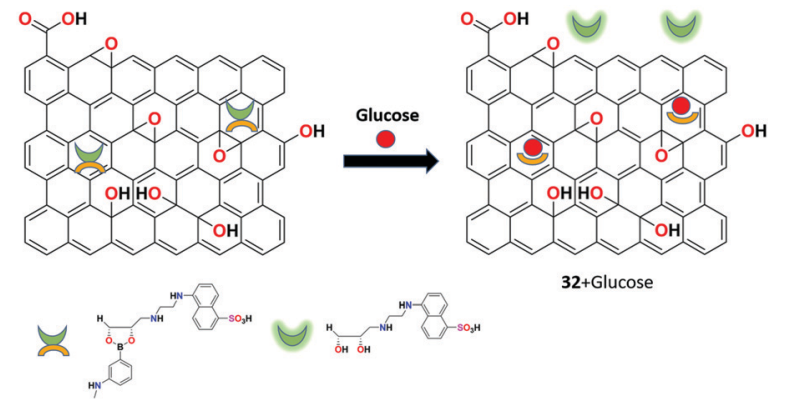

Fig. 35 Fluorescent detection of glucose molecule using receptor 32.

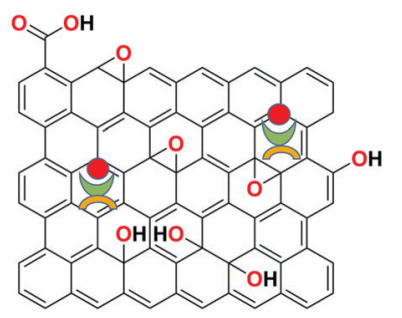

33

PVP/pyrene/APTS/rGO

Fig. 36 The structure of PVP/pyrene/APTS/rGO fluorescent receptor 33.

the single step electrospinning method for the detection of the nitroaromatic explosive vapor. ${ }^{96}$ The receptor showed high sensing performance toward TNT (2,4,6-trinitrotoluene) and DNT (dinitrotoluene) compared to other analogues with quenching efficiencies of $81 \%$ and $89 \%$, respectively, at room temperature within the exposure time of $540 \mathrm{~s}$. The binding was ascribed to the synergistic effects induced by the fast charge transfer, adsorption properties, and effective $\pi-\pi$ stacking of rGO and APTS (3-aminopropyltriethoxysilane).

Lee et al. demonstrated the graphene oxide-functionalized metal-organic fluorescent composite 34 for the chemosensor application of trinitrotoluene (TNT) molecular recognition. ${ }^{97}$ Sensor 34 was synthesized as the metal-organic framework (MOF) using azobenzoic acid-functionalized with grapheneoxide hydrogels in the presence of $\mathrm{Zn}^{2+}$ ions. The sensing applicability was experimented in the film state by exposing to trinitrotoluene (TNT) and dinitrotoluene (DNT) vapors. Within $10 \mathrm{~min}$ of continuous exposure, 98\% fluorescence quenching was observed due to charge transfer interactions.

A water-soluble GO functionalized by amine-modified mesoporous silica nanoparticles with poly( $p$-phenylenevinylene) (PPV) 35 was developed by Zhang and research group for the facile and sensitive fluorescent recognition of 2,4,6-trinitrotoluene (TNT) in aqueous solution. ${ }^{98}$ The receptor showed strong green fluorescence in aqueous solution and upon the addition of TNT molecule, the fluorescence emission was strongly suppressed through the FRET process due to the binding of TNT with the amine groups of the receptor. The detection limit for the 

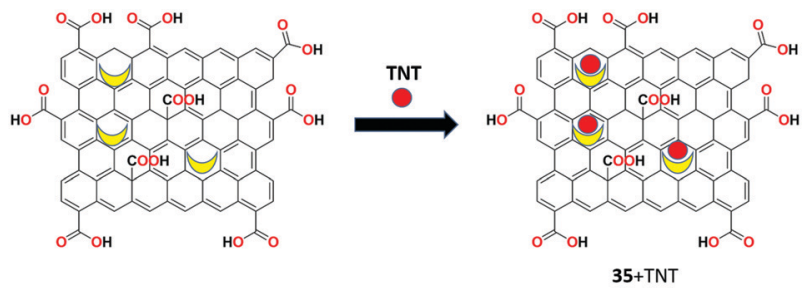

$Y$ PPV

Fig. 37 The binding process of receptor 35 with TNT.

quantitative recognition of TNT by receptor 35 was calculated to be $1.3 \times 10^{-7} \mathrm{M}$ (Fig. 37).

\subsection{Organic pollutants and dyes}

A dextran-fluorescein-functionalized rGO-based highly reproducible fluorescent "turn-on" sensor 36 was synthesized by Mitra et al. for the sensitive recognition of small organic pollutants. ${ }^{99}$ The detection system was made using reduced graphene oxidepolystyrenesulfonate composite loaded with the fluorescent probe dextran-fluorescein. The sensor produced low fluorescence due to the ET process between the rGO and dextran-fluorescein. However, upon the binding of various organic pollutants to receptor 36, strong $\pi-\pi$ interactions was formed, which overcome the weak noncovalent interactions. This results in the detachment of dextran-fluorescein from the graphene surface, exhibiting stronger fluorescence. In this sensitive and reproducible approach, various organic pollutants such as bisphenol A, 1-napthol, phenol, and picric acid were detected successfully in a small sample volume (Fig. 38).

The group of Huang utilized the fast and sensitive detection of synthetic organic dyes based on the fluorescein/rGO complex 37. ${ }^{100}$ The weak competitor (fluorescein) initially showed low fluorescence with rGO by the FRET process. During the displacement of the fluorescein moiety from the complex and upon binding with methylene blue (MB), stronger fluorescence was induced, which proves the competitive adsorption of the nanosheet between the synthetic organic dye and the fluorescent dye. The binding strategy was compared with the sunset yellow (SY) analyte with a detection limit of $1.15 \mathrm{ng} \mathrm{mL}^{-1}$ (Fig. 39).

Zhou et al. presented new rGO nanosheets 38 functionalized with carboxylated pillar[5]arene macrocycle via covalent bonds for the detection of organic dye molecules (Rhodamine 6G and

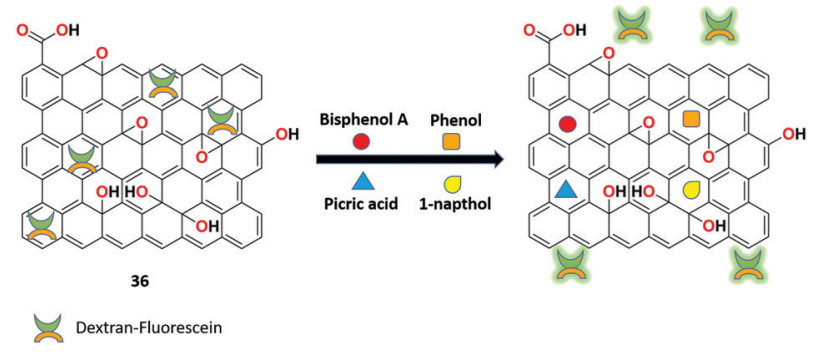

Fig. 38 The sensing approach of organic pollutants with receptor 36 .

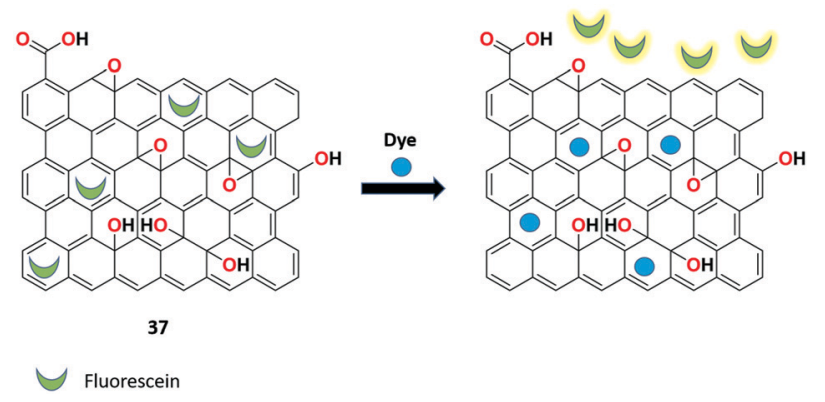

Fig. 39 The binding strategy of receptor 37 with synthetic organic dyes.

neutral red) and pesticides in aqueous solutions. ${ }^{101}$ Sensor 38 exhibits good water dispersibility compared to rGO and causes drastic fluorescence quenching upon the binding of analytes such as organic dyes and pesticides in aqueous solutions as a consequence of FRET or PET process in receptor 38 (Fig. 40).

\subsection{Antibiotics}

Bao et al. proposed a novel and highly selective GO and RhBPy [2]rotaxane-based nanocomposite as fluorescent chemosensor 39 for the recognition of doxorubicin (antibiotic) in $\mathrm{MeOH} / \mathrm{H}_{2} \mathrm{O}$ $(3: 2, \mathrm{v} / \mathrm{v})$ solution. ${ }^{102}$ Due to the strong noncovalent interactions via the FRET process, weak fluorescence emission was observed between GO and RhBPy [2]rotaxane. In the presence of doxorubicin, strong red fluorescence was obtained with high sensitivity and specificity among other antibiotics. Surprisingly, receptor 39 produces sharp response toward doxorubicin within $40 \mathrm{~s}$ and a detection limit of $0.0185 \mu \mathrm{M}$ (Fig. 41).

\subsection{RNA}

A novel technique by conjugating GO with the site-specific cleavage of an endonuclease was introduced by the group of $\mathrm{Tu}$ for the selective and sensitive recognition of microRNA (miRNA). ${ }^{103}$ The fluorescent receptor 40 was synthesized by assembling the FAM-labeled fluorophore (6-carboxyfluorescein) on the GO surface showing fluorescence quenching then it hybridized with the specific target (miR-126) and cleaved by RsaI endonuclease. After the cleavage of the formed duplex, strong fluorescence was obtained and readily detectable signals with a low detection limit of $\sim 3.0 \mathrm{fM}$ (at a signal/noise of 3 ) miR-126 with a linear range of 4 orders of magnitude. Also, this target sequence can be clearly discriminated from the
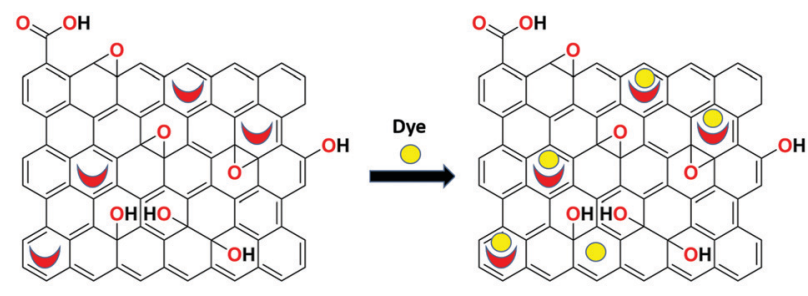

38

Carboxylated pillar[5]arene

Fig. 40 Schematic illustration of binding of dye molecules with receptor 38 . 


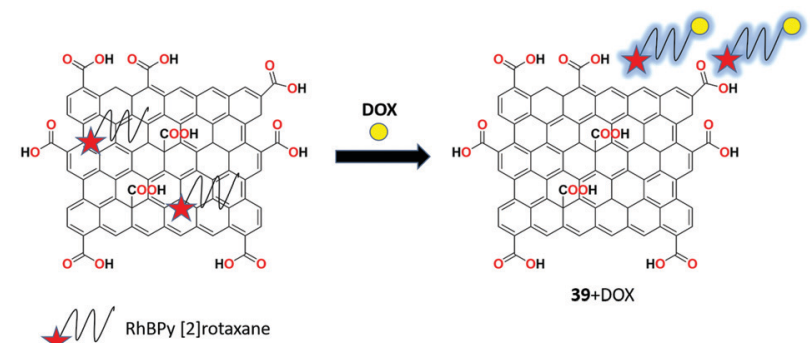

Fig. 41 The binding process of receptor 39 with doxorubicin.

single-base mismatched sequence and other miRNA sequences (Fig. 42).

\subsection{Lectins}

GO and glycosyl-based fluorescent probes 41 and 42 with AIE property were investigated by Jiang et al. for the recognition of lectin-sugar interactions in the NIR region and targeting in liver cells. ${ }^{104}$ Both fluorescent probes exhibited remarkable fluorescent enhancement selectively upon the addition of lectins with low detection limits of $3.8 \times 10^{-8} \mathrm{M}, 4.6 \times$ $10^{-8} \mathrm{M}$, and $1.4 \times 10^{-8} \mathrm{M}$ for ConA, LcA, and PNA, respectively. The selective binding of lectins was ascribed to the AIE mechanism, which was confirmed by scanning electron microscopy (SEM). Moreover, due to the specific sugar-receptor interactions, the liver cancer cell line expressing the transmembrane glycoprotein probe can be specifically targeted by 42 in a fluorescent manner (Fig. 43).
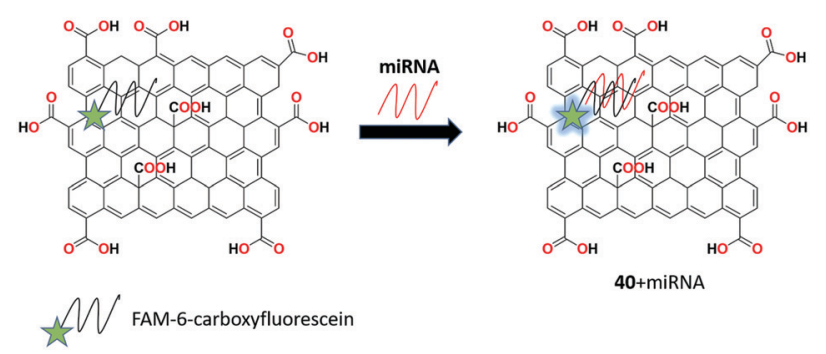

Fig. 42 The binding strategy of receptor $\mathbf{4 0}$ with miRNA.

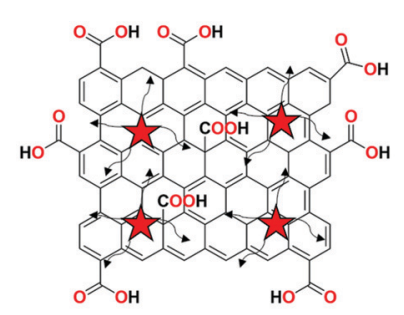

41

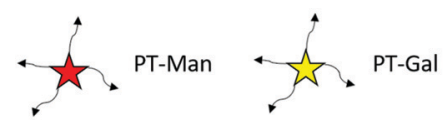

Fig. 43 The structures of fluorescent probes $\mathbf{4 1}$ and $\mathbf{4 2}$.

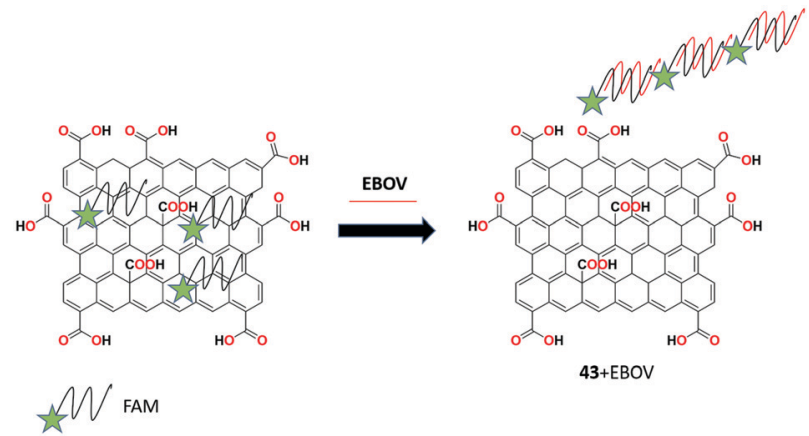

Fig. 44 The schematic representation of the binding of receptor 43 with the EBOV gene.

\subsection{Virus}

Recently, Wen et al. reported a simple FAM-labeled GO 43 assisted rolling circle amplification (RCA) platform for the effective recognition of Ebola virus (EBOV) in aqueous solution. ${ }^{105}$ Fluorescence quenching was observed in the absence of EBOV gene for fluorescein ambidate (FAM)-labeled probe $\mathbf{4 3}$ on the surface of GO. Upon the addition of the EBOV gene, strong fluorescence was obtained due to the cleavage of the FAM-labeled probe from the GO surface. The detection limit was calculated to be $1.4 \mathrm{pM}$ for the selective recognition of EBOV. Biosensor $\mathbf{4 3}$ was also used to determine the EBOV gene in $1 \%$ human serum samples with satisfactory results (Fig. 44).

\section{Conclusion}

To sum up, this is the first kind of review that explores functionalized graphene oxide nanomaterials as fluorimetric probes for the detection of various analytes using supramolecular chemistry principles. Discussion has been made based on the fluorescent sensing approach by the functionalized GO and rGO materials by various research teams. Comparatively, GO and rGO nanomaterials have superior characteristics such as photostability, nontoxicity, bio-compatibility, water solubility, and cost-efficiency compared to many organic dye compounds and inorganic materials. However, graphene-based nanomaterials hamper the sensing and complexation applications by the lack of functional groups in it. The properties of the materials could be enhanced by the functionalization variety of organic fluorophores, organic acids, polymers, organic dyes, inorganic nanoparticles, macrocyclic compounds, rotaxanes, DNA, metal oxides, and chemodosimeter molecules to yield modified GO and rGO nanomaterials for variable sensing applications. In view of the current state-of-the-art, the detection of various biologically and environmentally significant analytes has been illustrated based on several sensing mechanisms such as PET, FRET, ICT, ET, ESIPT, AIE, and displacement approach.

In the future, researchers should start to make headway in the field of fluorescent chemosensors by functionalizing graphene-based nanomaterials toward the tuning of photophysical properties. As a consequence, the problems in the prevailing system such as the specific recognition of various 
pollutants in the environment, toxic elements in medical, hazardous materials in chemicals, and contaminants in biological fields can be addressed by developing efficient, elegant, and economic fluorescent probes. Therefore, the specificity and sensitivity of the materials toward biologically/environmentally important molecules, metal ions, anions, etc., with various sensing phenomena could be revealed. At present, novel receptors with excellent photophysical properties are vital to meet the essential requirements of the monitoring bodies. In general, organic-based surface-modified graphene nanomaterials have superior absorption capacities for a wide spectrum of analytes due to their specific guest binding compared with other conventional adsorbents. In addition, the modification was specifically driven by the covalent and noncovalent interactions including electrostatic forces, $\pi-\pi$ interaction, and hydrogen bonding between $\mathrm{GO} / \mathrm{rGO}$ and the functionalizing material to render stronger photophysical properties for fluorescent chemosensor applications. Lastly, the research problems such as the enhancement of the biocompatibility and the photophysical properties of the GO/rGO-based functionalized nanomaterials must be addressed by extensive and dedicated research to expand the qualitative and quantitative applicability. Hence, we conclude that this review paves a path in the field of $2 \mathrm{D}$ material-based fluorescent chemosensors, which potentially finds several important applications in diverse research fields, including the thrust areas such as Food, Water, Energy, and Healthcare, which eventually solve the problems of humankind.

\section{Conflicts of interest}

There are no conflicts to declare.

\section{Acknowledgements}

The authors gratefully thank the financial support of the SERBEMR grant by the DST (Sanction No. SERB-EMR/2016/005692). S. Suguna is very much thankful to Karunya Institute of Technology and Sciences for providing the financial support through Evangeline Dhinakaran Doctoral Fellowship.

\section{Notes and references}

1 O. S. Wolfbeis and B. M. Weidgans, in Optical Chemical Sensors, ed. F. Baldini, A. N. Chester, J. Homola and S. Martellucci, NATO Science Series II: Mathematics, Physics and Chemistry, Chapter 2: Fiber optic chemical sensors and biosensors: a view back, Springer, Netherlands, 2006, pp. 17-44.

2 T. W. Bell and N. M. Hext, Chem. Soc. Rev., 2004, 33, 589-598.

3 H. Zhang, C. Tong, J. Sha, B. Liu and C. Lü, Sens. Actuators, B, 2015, 206, 181-189.

4 L. Prodi, New J. Chem., 2005, 29, 20-31.

5 M. Wang, G. Zhang, D. Zhang, D. Zhu and B. Z. Tang, J. Mater. Chem., 2010, 20, 1858-1867.
6 Z. Kowser, U. Rayhan, T. Akther, C. Redshaw and T. Yamato, Mater. Chem. Front., 2021, 5, 2173-2200.

7 D. Wu, A. C. Sedgwick, T. Gunnlaugsson, E. U. Akkaya, J. Yoon and T. D. James, Chem. Soc. Rev., 2017, 46, 7105-7123.

8 J. Wu, W. Liu, J. Ge, H. Zhang and P. Wang, Chem. Soc. Rev., 2011, 40, 3483-3495.

9 P. Roy, Coord. Chem. Rev., 2021, 427, 213562.

10 A. K. Das and S. Goswami, Sens. Actuators, B, 2017, 245, 1062-1125.

11 G. Rocchitta, A. Spanu, S. Babudieri, G. Latte, G. Madeddu, G. Galleri, S. Nuvoli, P. Bagella, M. I. Demartis, V. Fiore, R. Manetti and P. A. Serra, Sensors, 2016, 16(6), 780.

12 M. I. Gaviria-Arroyave, J. B. Cano and G. A. Peñuela, Talanta Open, 2020, 2, 100006.

13 X. Lu, W. Zhu, Y. Xie, X. Li, Y. Gao, F. Li and H. Tian, Chem. - Eur. J., 2010, 16, 8355-8364.

14 R. Kumar, S. Ravi, C. Immanuel David and R. Nandhakumar, Arab. J. Chem., 2021, 14, 102911.

15 A. Gangopadhyay, K. Maiti, S. S. Ali, A. K. Pramanik, U. N. Guria, S. K. Samanta, R. Sarkar, P. Datta and A. K. Mahapatra, Anal. Methods, 2018, 10, 2888-2894.

16 H. Goh, Y. G. Ko, T. K. Nam, A. Singh, N. Singh and D. O. Jang, Tetrahedron Lett., 2016, 57, 4435-4439.

17 S. M. Hossain, K. Singh, A. Lakma, R. N. Pradhan and A. K. Singh, Sens. Actuators, B, 2017, 239, 1109-1117.

18 V. Tharmaraj, S. Devi and K. Pitchumani, Analyst, 2012, 137, 5320-5324.

19 P. Taya, B. Maiti, V. Kumar, P. De and S. Satapathi, Sens. Actuators, B, 2018, 255, 2628-2634.

20 C. Yuan, S. Li, Y. Wu, L. Lu and M. Zhu, Sens. Actuators, B, 2017, 242, 1035-1042.

21 S. Sinha, B. Chowdhury and P. Ghosh, Inorg. Chem., 2016, 55, 9212-9220.

22 Y. Li, K. Xu, Y. Si, C. Yang, Q. Peng, J. He, Q. Hu and K. Li, Dyes Pigm., 2019, 171, 107682.

23 N. Na, F. Wang, J. Huang, C. Niu, C. Yang, Z. Shang, F. Han and J. Ouyang, RSC Adv., 2014, 4, 35459-35462.

24 X. Yang, X. Chen, X. Lu, C. Yan, Y. Xu, X. Hang, J. Qu and R. Liu, J. Mater. Chem. C, 2016, 4, 383-390.

25 C. Immanuel David, N. Bhuvanesh, H. Jayaraj, A. Thamilselvan, D. Parimala devi, A. Abiram, J. Prabhu and R. Nandhakumar, ACS Omega, 2020, 5(6), 3055-3072.

26 G. Prabakaran, K. Velmurugan, R. Vickram, C. Immanuel David, A. Thamilselvan, J. Prabhu and R. Nandhakumar, Spectrochim. Acta, Part A, 2020, 246, 119018.

27 Y. Jeong and J. Yoon, Inorg. Chim. Acta, 2012, 381, 2-14.

28 K. Velmurugan, R. Vickram, C. V. Jipsa, R. Karthick, G. Prabakaran, S. Suresh, J. Prabhu, G. Velraj, L. Tang and R. Nandhakumar, Food Chem., 2021, 348, 129098.

29 K. Maiti, A. K. Mahapatra, A. Gangopadhyay, R. Maji, S. Mondal, S. S. Ali, S. Das, R. Sarkar, P. Datta and D. Mandal, ACS Omega, 2017, 2, 1583-1593.

30 S. Manigandan, A. Muthusamy, R. Nandhakumar and C. Immanuel David, J. Mol. Struct., 2020, 1208, 127834.

31 H. Kuzhandaivel, S. B. Basha, I. D. Charles, N. Raju, U. Singaravelu and K. Sivalingam Nallathambi, J. Fluoresc., 2021, 1-13. 
32 C. I. David, G. Prabakaran, K. Sundaram, S. Ravi, D. P. Devi, A. Abiram and R. Nandhakumar, J. Hazard. Mater., 2021, 419, 126449.

33 C. Immanuel David, G. Prabakaran and R. Nandhakumar, Microchem. J., 2021, 169, 106590.

34 X. Yu Kong, L. J. Hou, X. Qing Shao, S. M. Shuang, Y. Wang and C. Dong, Spectrochim. Acta, Part A, 2019, 208, 131-139.

35 P. R. Dongare, A. H. Gore, G. B. Kolekar and B. D. Ajalkar, Luminescence, 2020, 35, 231-242.

36 K. Velmurugan, R. Vickram, R. Karthick, C. V. Jipsa, S. Suresh, G. Prabakaran, J. Prabhu, G. Velraj and R. Nandhakumar, J. Photochem. Photobiol., A, 2020, 401, 112737.

37 K. S. Novoselov, V. I. Fal'Ko, L. Colombo, P. R. Gellert, M. G. Schwab and K. Kim, Nature, 2012, 490, 192-200.

38 A. H. Castro Neto, F. Guinea, N. M. R. Peres, K. S. Novoselov and A. K. Geim, Rev. Mod. Phys., 2009, 81, 109-162.

39 A. K. Geim and K. S. Novoselov, Nat. Mater., 2007, 6, 183-191.

40 H. Huang, Z. Li, J. She and W. Wang, J. Appl. Phys., 2012, 111, 054317.

41 A. Mathkar, D. Tozier, P. Cox, P. Ong, C. Galande, K. Balakrishnan, A. Leela Mohana Reddy and P. M. Ajayan, J. Phys. Chem. Lett., 2012, 3, 986-991.

42 M. Li, S. K. Cushing, X. Zhou, S. Guo and N. Wu, J. Mater. Chem., 2012, 22, 23374-23379.

43 J. Sun, S. Yang, Z. Wang, H. Shen, T. Xu, L. Sun, H. Li, W. Chen, X. Jiang, G. Ding, Z. Kang, X. Xie and M. Jiang, Part. Part. Syst. Charact., 2015, 32, 434-440.

44 S. K. Cushing, W. Ding, G. Chen, C. Wang, F. Yang, F. Huang and N. Wu, Nanoscale, 2017, 9, 2240-2245.

45 S. Zhu, J. Zhang, C. Qiao, S. Tang, Y. Li, W. Yuan, B. Li, L. Tian, F. Liu, R. Hu, H. Gao, H. Wei, H. Zhang, H. Sun and B. Yang, Chem. Commun., 2011, 47, 6858-6860.

46 S. Stankovich, R. D. Piner, X. Chen, N. Wu, S. T. Nguyen and R. S. Ruoff, J. Mater. Chem., 2006, 16, 155-158.

47 Y. Dong, J. Shao, C. Chen, H. Li, R. Wang, Y. Chi, X. Lin and G. Chen, Carbon, 2012, 50, 4738-4743.

48 J. Shang, L. Ma, J. Li, W. Ai, T. Yu and G. G. Gurzadyan, Sci. Rep., 2012, 2, 1-8.

49 D. R. Dreyer, S. Park, C. W. Bielawski and R. S. Ruoff, Chem. Soc. Rev., 2010, 39, 228-240.

50 G. Eda and M. Chhowalla, Adv. Mater., 2010, 22, 2392-2415.

51 A. Chandrasoma, A. A. A. Hamid, A. E. Bruce, M. R. M. Bruce and C. P. Tripp, Anal. Chim. Acta, 2012, 728, 57-63.

52 D. Wilson, M. Del Valle, S. Alegret, C. Valderrama and A. Florido, Talanta, 2012, 93, 285-292.

53 H. Bingol, E. Kocabas, E. Zor and A. Coskun, Talanta, 2010, 82, 1538-1542.

54 K. P. Loh, Q. Bao, G. Eda and M. Chhowalla, Nat. Chem., 2010, 2, 1015-1024.

55 X. Jiang, G. Ruan, Y. Huang, Z. Chen, H. Yuan and F. Du, J. Sep. Sci., 2020, 43, 1544-1557.
56 P. Zheng and N. Wu, Chem. - Asian J., 2017, 12, 2343-2353.

57 J. Chang, G. Zhou, E. R. Christensen, R. Heideman and J. Chen, Anal. Bioanal. Chem., 2014, 406, 3957-3975.

58 D. D. Zhang, S. Z. Zu and B. H. Han, Carbon, 2009, 47, 2993-3000.

59 S. Niyogi, E. Bekyarova, M. E. Itkis, J. L. McWilliams, M. A. Hamon and R. C. Haddon, J. Am. Chem. Soc., 2006, 128, 7720-7721.

60 M. Kumar, K. Singh, S. K. Dhawan, K. Tharanikkarasu, J. S. Chung, B. S. Kong, E. J. Kim and S. H. Hur, Chem. Eng. J., 2013, 231, 397-405.

61 P. K. Nayak, Recent Advances in Graphene Research, InTech, 2016.

62 Photoenergy and Thin Film Materials, ed. X. Yang, Wiley, 2019.

63 Y. W. He, Y. Feng, L. W. Kang and X. L. Li, J. Chem., 2017, 2017, 1-5.

64 H. N. Abdelhamid and H. F. Wu, Microchim. Acta, 2015, 182, 1609-1617.

65 W. T. Huang, Y. Shi, W. Y. Xie, H. Q. Luo and N. B. Li, Chem. Commun., 2011, 47, 7800-7802.

66 D. Sahu, N. Sarkar, P. Mohapatra and S. K. Swain, Microchem. J., 2020, 154, 104577.

67 D. Dinda, B. K. Shaw and S. K. Saha, ACS Appl. Mater. Interfaces, 2015, 7, 14743-14749.

68 A. K. Akhila and N. K. Renuka, New J. Chem., 2019, 43, 1001-1008.

69 F. S. Awad, K. M. AbouZied, A. M. Bakry, W. M. Abou ElMaaty, A. M. El-Wakil and M. S. El-Shall, Anal. Chim. Acta, 2020, 1140, 111-121.

70 J. Huang, Q. Zheng, J. K. Kim and Z. Li, Biosens. Bioelectron., 2013, 43, 379-383.

71 X. Li, K. Fan, W. Kang, R. Yang, B. Qu and L. Lu, Microchim. Acta, 2019, 186, 1-9.

72 Y. Liu, M. Deng, X. Tang, T. Zhu, Z. Zang, X. Zeng and S. Han, Sens. Actuators, B, 2016, 233, 25-30.

73 R. Cheng, L. Li, S. Ou, Y. Bu, C. Ge, L. Dai and Y. Xue, RSC Adv., 2016, 6, 36218-36222.

74 H. Goldooz, A. Badiei, G. Shiravand, J. B. Ghasemi and G. Mohammadi Ziarani, J. Mater. Sci. Mater. Electron., 2019, 30, 17693-17705.

75 N. Bhuvanesh, K. Velmurugan, S. Suresh, T. Sakthivel and R. Nandhakumar, Nanosyst. Physics, Chem. Math., 2016, 542-546.

76 Y. Wen, F. Xing, S. He, S. Song, L. Wang, Y. Long, D. Li and C. Fan, Chem. Commun., 2010, 46, 2596-2598.

77 H. Lv, S. Li, Y. Liu, G. Wang, X. Li, Y. Lu and J. Wang, Microchim. Acta, 2015, 182, 2513-2520.

78 A. Pandiyarajan, D. J. Dmonte, N. Bhuvanesh, S. Suresh, B. Vidhya and R. Nandhakumar, J. Nanosci. Nanotechnol., 2019, 19, 5189-5194.

79 D. J. Dmonte, A. Pandiyarajan, N. Bhuvanesh, S. Suresh and R. Nandhakumar, Mater. Lett., 2018, 227, 154-157.

80 N. R. David John Dmonte, A. Pandiyarajan, R. Swaminathan, S. Ayyasamy and V. Bhojan, Asian J. Chem., 2021, in press.

81 S. Elsie, A. Green, D. Rubavathi, A. Angamuthu, B. Gopal and J. Bhagavathsingh, ACS Omega, 2019, 4, 22431-22437. 
82 X. Shi, W. Gu, W. Peng, B. Li, N. Chen, K. Zhao and Y. Xian, ACS Appl. Mater. Interfaces, 2014, 6, 2568-2575.

83 X. Chen, X. Wang, Z. Lu, H. Luo, L. Dong, Z. Ji, F. Xu, D. Huo and C. Hou, Sens. Actuators, B, 2020, 311, 127898.

84 A. M. Şenol, Y. Onganer and K. Meral, Sens. Actuators, B, 2017, 239, 343-351.

85 J. B. Asha and P. Suresh, ACS Sustainable Chem. Eng., 2020, 8, 14301-14311.

86 B. Eftekhari-Sis, Z. Rezazadeh, A. Akbari and M. Amini, J. Fluoresc., 2018, 28, 1173-1180.

87 B. Eftekhari-Sis and S. Mirdoraghi, Media Nanochem. Res., 2016, 1, 214-221.

88 P. Ramesh and B. Jebasingh, Mater. Chem. Phys., 2019, 222, 45-54.

89 C. Wang, S. Yang, M. Yi, C. Liu, Y. Wang, J. Li, Y. Li and R. Yang, ACS Appl. Mater. Interfaces, 2014, 6, 9768-9775.

90 N. Adachi, M. Yoshinari, E. Suzuki and M. Okada, J. Fluoresc., 2017, 27, 1449-1456.

91 Y. Bai, F. Feng, L. Zhao, Z. Chen, H. Wang and Y. Duan, Analyst, 2014, 139, 1843-1846.

92 R. Blessy Pricilla, N. Bhuvanesh, C. Immanuel David, S. Murugan and R. Nandhakumar, Mater. Today Proc., 2021, DOI: 10.1016/j.matpr.2020.11.466.

93 R. N. R. Blessy Pricilla, N. Bhuvanesh, B. Vidhya and S. Murugan, Exploration of GO-CuO nanocomposite for its antibacterial properties and potential application as a chemosensor in the sensing of L-leucine: Inorganic and
Nano-Metal Chemistry: Vol 0, No 0, https:/www.tandfon line.com/doi/abs/10.1080/24701556.2021.1956958?journal Code=lsrt21, (accessed 6 August 2021).

94 R. Cheng, Y. Peng, C. Ge, Y. Bu, H. Liu, H. Huang, S. Ou, Y. Xue and L. Dai, Microchim. Acta, 2017, 184, 3521-3528.

95 S. K. Basiruddin and S. K. Swain, Mater. Sci. Eng., C, 2016, 58, 103-109.

96 L. Guo, B. Zu, Z. Yang, H. Cao, X. Zheng and X. Dou, Nanoscale, 2014, 6, 1467-1473.

97 J. H. Lee, S. Kang, J. Jaworski, K.-Y. Kwon, M. L. Seo, J. Y. Lee and J. H. Jung, Chem. - Eur. J., 2012, 18, 765-769.

98 H. Zhang, L. Feng, B. Liu, C. Tong and C. Lü, Dyes Pigm., 2014, 101, 122-129.

99 R. Mitra and A. Saha, ACS Sustainable Chem. Eng., 2017, 5, 604-615.

100 S. T. Huang, Y. Shi, N. B. Li and H. Q. Luo, Analyst, 2012, 137, 2593-2599.

101 T. Zhou, H. Yu, M. Liu and Y.-W. Yang, Chin. J. Chem., 2015, 33, 125-130.

102 X. Bao, J. Shi, J. Zhu and X. Wang, Sens. Actuators, B, 2016, 237, 380-386.

103 Y. Tu, W. Li, P. Wu, H. Zhang and C. Cai, Anal. Chem., 2013, 85, 2536-2542.

104 T. Jiang, H. Tan, Y. Sun, J. Wang, Y. Hang, N. Lu, J. Yang, X. Qu and J. Hua, Sens. Actuators, B, 2018, 261, 115-126.

105 J. Wen, W. Li, J. Li, B. Tao, Y. Xu, H. Li, A. Lu and S. Sun, Sens. Actuators, B, 2016, 227, 655-659. 